\title{
Continuous Nucleation and Size Dependent Growth Kinetics of Indium Phosphide Nanocrystals
}

\author{
Brandon M. McMurtry, Kevin Qian, Joseph K. Teglasi, Anindya K. Swarnakar, Jonathan De Roo, \\ and Jonathan S. Owen*
}

Cite This: https://dx.doi.org/10.1021/acs.chemmater.0c01561

Read Online

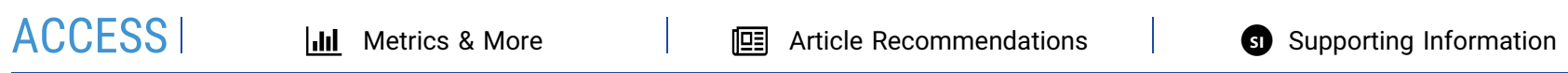

ABSTRACT: Aminophosphines derived from $N, N^{\prime}$-disubstituted ethylenediamines $\left(\mathrm{R}-\mathrm{N}(\mathrm{H}) \mathrm{CH}_{2} \mathrm{CH}_{2} \mathrm{~N}(\mathrm{H})-\mathrm{R} ; \mathrm{R}\right.$ = ortho-tolyl, phenyl, benzyl, iso-propyl, and $n$-octyl) were used to adjust the kinetics of InP nanocrystal formation by more than 1 order of magnitude. Ultraviolet-visible absorption and ${ }^{31} \mathrm{P}$ nuclear magnetic resonance measurements demonstrate that the rate of nanocrystal formation is limited by the precursor reactivity. At low temperature $\left(180^{\circ} \mathrm{C}\right)$, crystal nucleation is concurrent with growth throughout the reaction, rather than occurring in a burst at early times. The low temperature produces a narrow range of small sizes $(d=4.2-4.9$

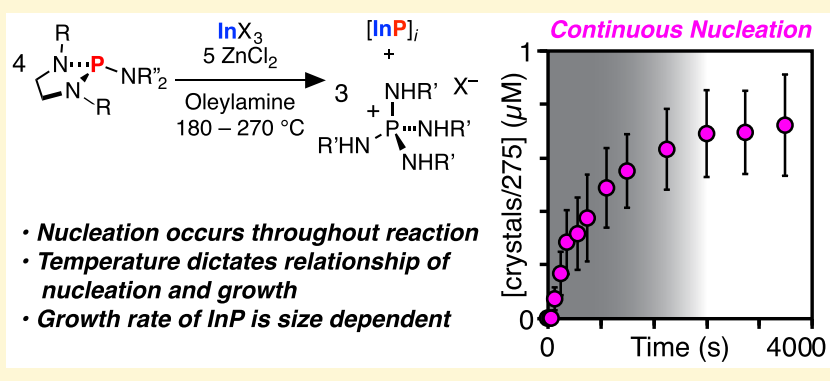
$\mathrm{nm}$ ) regardless of the precursor used. Higher temperatures (up to

$\left.270{ }^{\circ} \mathrm{C}\right)$ promote growth to larger sizes $(d \leq 7.8 \mathrm{~nm})$, shorten the nucleation period, and create conditions where the final size is controlled by the precursor conversion reactivity. The temperature dependence is proposed to arise from growth kinetics that slow as the nanocrystal size increases, a novel surface attachment limited size distribution-focusing mechanism. Such a mechanism supports a narrow size distribution without separating the nucleation and growth phases.

\section{INTRODUCTION}

InP nanocrystals are leading replacements for CdSe nanocrystals in solid-state lighting, ${ }^{1}$ luminescent displays, ${ }^{2,3}$ and biological imaging. ${ }^{4,5}$ However, their broad emission linewidths, chemical instability, moderate photoluminescence quantum yields, and poor absorptivity at blue pump wavelengths present significant limitations that have slowed their adoption. ${ }^{6,7}$ Although important advances in the synthesis of InP nanocrystals have recently appeared, ${ }^{8-11}$ it remains difficult to modify the microstructure of InP nanocrystals to address the performance limitations described above. Welldocumented synthetic difficulties are partly the result of a limited mechanistic understanding of InP nanocrystal formation. Moreover, leading mechanistic hypotheses suggest that InP formation does not follow a typical LaMer-like sequence. $^{12-17}$ A deeper understanding of InP nanocrystal formation mechanisms is therefore of great interest currently. ${ }^{18-23}$

The majority of synthetic approaches to InP use indium carboxylates, $\operatorname{In}\left(\mathrm{O}_{2} \mathrm{CR}\right)_{3}(\mathrm{R}=n$-alkyl $)$, and tris-trimethylsilylphosphine $\left((\mathrm{TMS})_{3} \mathrm{P}\right)$ to produce nanocrystals with narrow optical absorption and photoluminescence (PL) features after shelling with $\mathrm{ZnS}$ or $\mathrm{ZnSe}\left(\mathrm{PL}_{\mathrm{fwhm}}=36-50 \mathrm{~nm}\right) \cdot{ }^{6,19,20}$ Unlike II-VI and IV-VI nanocrystals, where the kinetics of precursor conversion are rate limiting and the extent of nucleation can be controlled by the precursor reactivity, ${ }^{14,15,17,19,24,25}$ the nucleation and growth of III-V nanocrystals are, thus far,
Scheme 1. Synthesis of InP from Aminophosphines, Metal Halides, and $\mathbf{R}^{\prime}-\mathrm{NH}_{2}\left(\mathrm{R}^{\prime}=\right.$ Oleyl $)$

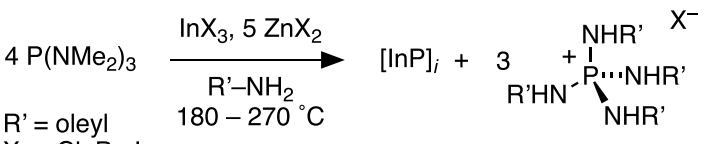

$$
\begin{aligned}
& \mathrm{X}=\mathrm{Cl}, \mathrm{Br}, \mathrm{I}
\end{aligned}
$$

less sensitive to the precursor design. For example, silyl, germanyl, and stannyl pnictide derivatives adjust the kinetics of InP formation from indium carboxylates, but have a minor effect on the final size or dispersity..$^{20,24-26}$ To explain these results, a mechanism has been proposed where the formation of stable cluster intermediates decouples the influence of the precursor reactivity on the nucleation. ${ }^{20}$

Indium(III) halides (halide $=\mathrm{Cl}, \mathrm{Br}$, and $\mathrm{I}$ ) and trisaminophosphines (e.g., $\left.\mathrm{P}\left(\mathrm{NMe}_{2}\right)_{3}\right)$ can also be used to synthesize InP nanocrystals, albeit with broader optical features (absorbance full-width at half-maxima (fwhm): 48-80 $\mathrm{nm}) .^{22,27,28}$ Mechanistic studies have shown that the amino-

Received: April 11, 2020

Revised: April 21, 2020 
phosphine precursor rapidly transaminates with the oleylamine solvent before undergoing redox disproportionation to $\mathrm{InP}$, according to Scheme $1.22,29,30$ Although the nanocrystal formation kinetics, polydispersity, and final size are sensitive to the metal halide coreactant, it is unclear whether the aminophosphine conversion reaction shown in Scheme 1 limits the kinetics of nucleation and growth.

We hypothesized that aminophosphine derivatives would provide a straightforward approach to adjust the kinetics of InP formation and probe its influence on the nanocrystal formation. By accessing a wide range of reactivity, the solute production kinetics can be decoupled from the reaction temperature, allowing the influence of temperature on the crystal growth phase to be independently probed. In particular, we sought aminophosphines that produce solute more slowly than it is consumed by crystal growth (precursor conversion limited growth), conditions that allow the extent of nucleation and the final size to be controlled in other material systems. These conditions can also evaluate whether the formation of clusters decouples the solute supply from the growth.

Our effort led to the surprising conclusion that crystal nucleation occurs slowly and steadily at low reaction temperatures where nanocrystals are resistant to growth, while higher temperatures support a more burst-like, albeit slow, nucleation process. The slow continuous nucleation kinetics starkly contrast with the LaMer model but nonetheless provide narrow size distributions. These results can be explained with a model where growth kinetics are limited by attachment and depend on the nanocrystal size-a novel mechanism that can enforce a narrow size distribution.

\section{RESULTS}

Cyclic ethylenediaminophosphines (1-5) are prepared in a two-step sequence from phosphorus trichloride via the corresponding diaminochlorophosphine (Scheme 2). ${ }^{31-36} \mathrm{~A}$

Scheme 2. Aminophosphine Precursors Used in This Study<smiles>Cc1cccc(P)c1N1CCN([O-])P1N(C)C</smiles><smiles>NP[PH]1(c2ccccc2)c2ccccc2P2N(c3ccccc3)CCN21</smiles><smiles>CCCCN1P2CCN(C(C)C)P1N(CC)C2</smiles><smiles>[R17]N1N(c2ccccc2)CCN2CN(Cc3ccccc3)P1C2</smiles><smiles>[CH2+]CCCCC</smiles>

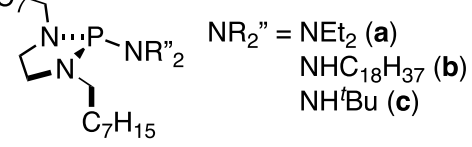

5

variety of $N, N^{\prime}$ disubstituted ethylenediamines, including sterically bulky $N, N^{\prime}-\operatorname{di}$ (iso-propyl) and $N, N^{\prime}$-di(ortho-tolyl) derivatives 1 and 3, could be prepared in good yield and purity.

InP nanocrystals are prepared from 1 to 5 , adapting conditions previously optimized for $\mathrm{P}\left(\mathrm{NMe}_{2}\right)_{3}$ (Figure 1). ${ }^{22,27,28}$ Four equivalents of $\mathbf{1 - 5}$ are swiftly injected into a colorless solution of indium(III) halide ( $\mathrm{InX}_{3}, \mathrm{X}=\mathrm{Cl}, \mathrm{Br}$, or I), zinc chloride, and oleylamine at temperatures between 180 and $270{ }^{\circ} \mathrm{C}$. Studies have shown that zinc halides improve the spectral linewidths and participate in the precursor conversion. ${ }^{27,30}$ Above $250{ }^{\circ} \mathrm{C}$, ethylenediamines and cyclic aminophosphines with aryl substituents (1 and 2) are unstable

A
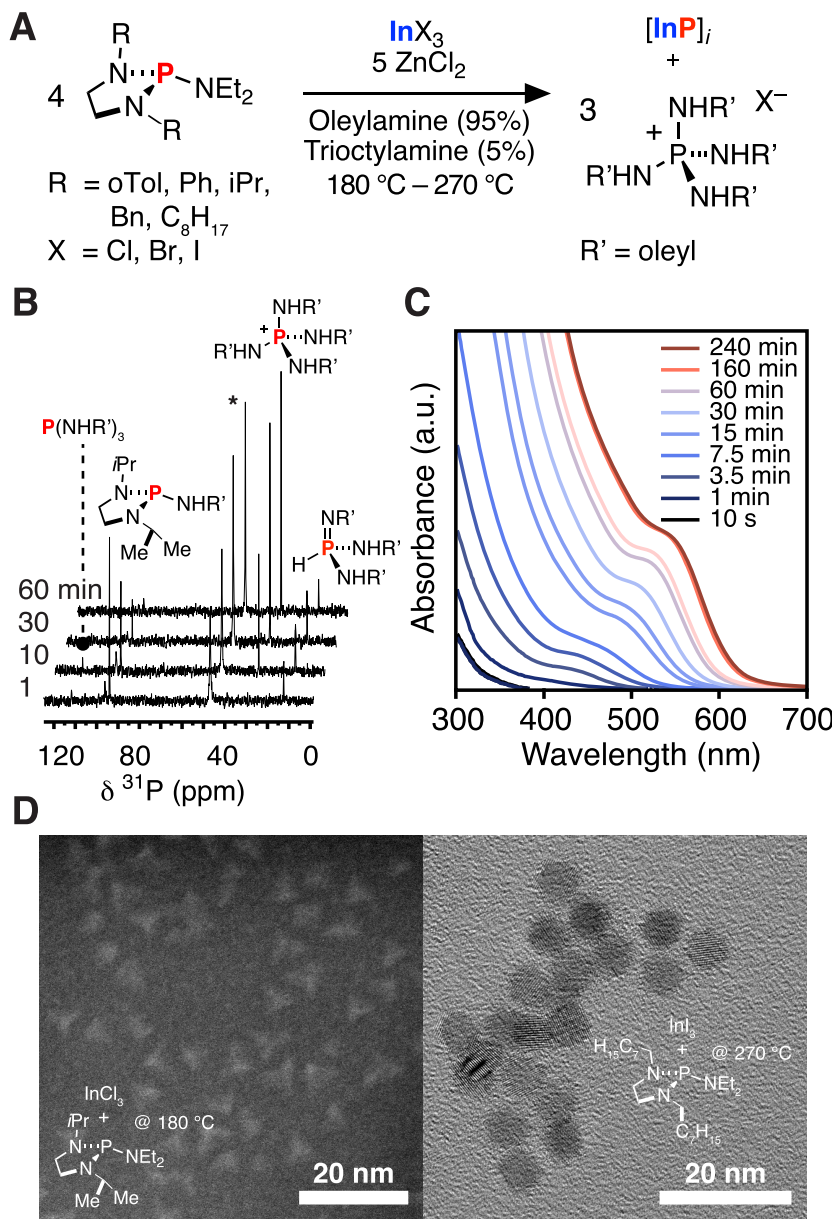

Figure 1. (A) Reaction scheme for the conversion of 1-5 and indium(III) halides to InP. (B) ${ }^{31} \mathrm{P}\left\{{ }^{1} \mathrm{H}\right\}$ NMR spectra (note that $(*)$ indicates a tri- $n$-octylphosphine oxide internal standard) and (C) $\mathrm{UV}$-vis absorption spectra of timed reaction aliquots for an InP reaction with $\mathrm{InI}_{3}$ and 3a at $180{ }^{\circ} \mathrm{C}$. (D) STEM image (left) for the reaction of $\mathrm{InCl}_{3}$ and $3 \mathrm{a}$ at $180{ }^{\circ} \mathrm{C}$ and TEM image (right) of nanocrystals from the reaction of $\mathrm{InI}_{3}$ and $\mathbf{5 a}$ at $270{ }^{\circ} \mathrm{C}$.

and form an unidentified black mixture, while 3-5 and their parent diamines appear stable up to $290{ }^{\circ} \mathrm{C}$. Thus, fewer precursors were functional at the highest temperatures evaluated here.

As described previously, the yield of InP can be determined by measuring the optical absorption at $\lambda=413 \mathrm{~nm} .^{27}$ At 413 $\mathrm{nm}$, a size independent extinction coefficient has been calculated and the absorption from solutes such as clusters with less than $\sim 20 \mathrm{InP}$ units is negligible. ${ }^{20,37}$ The yield of InP nanocrystals is compared with the conversion of the aminophosphine as measured by quantitative ${ }^{31} \mathrm{P}$ NMR spectroscopy (Figure 2A). When accounting for the formation of reactive intermediates, these measurements confirm that the yield of InP matches the conversion of molecular precursors. Mass balance measurements show that $>90 \pm 10 \%$ of $\mathrm{InP}$ produced by the precursor conversion is accounted for by the absorbance at $\lambda=413 \mathrm{~nm}$ (see the Supporting Information). The precursor conversion kinetics can, therefore, be monitored indirectly by following the absorption of nanocrystals at $\lambda=$ $413 \mathrm{~nm}$.

Once the yield of $\mathrm{InP}$ reaches its maximum value, the nanocrystals are isolated and purified. Powder X-ray diffraction and transmission electron microscopy (Figures $1 \mathrm{D}$ and S1- 


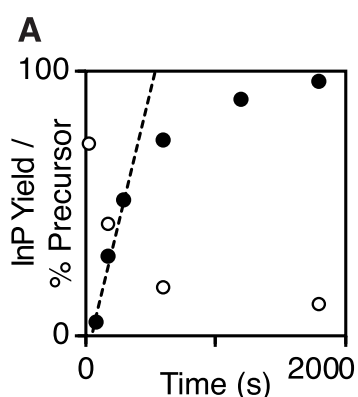

B

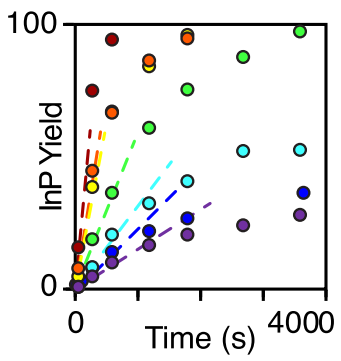

Figure 2. (A) Percentage of InP formed (black) and precursor species remaining (white), and linear fit of early time points to determine $Q_{0}$ (dashed line) for an InP reaction using 1c. (B) InP yield (points) and $Q_{0}$ fits (dashed lines) of $\mathrm{P}\left(\mathrm{NEt}_{2}\right)_{3}$ (red), $\mathbf{1 b}$ (orange), $\mathrm{P}\left(\mathrm{NMe}_{2}\right)_{3}$ (yellow), 3a (green), $\mathbf{2 b}$ (light blue), 5a (dark blue), and $\mathbf{4 a}$ (purple) under InP-forming conditions shown in Figure 1A.

S3) verify that the nanocrystals have a zincblende crystal structure and a quasi-tetrahedral shape at small sizes which becomes spherical at large sizes. Nanocrystal sizes are estimated from the energy of the absorption maximum using a previously published sizing curve and could be tuned from $d$ $=4.2-7.8 \mathrm{~nm}$ by adjusting the synthesis temperature and aminophosphine structure (see the Experimental Section and Supporting Information). ${ }^{28}$

Reactions conducted with $\mathrm{InI}_{3}$ at $180{ }^{\circ} \mathrm{C}$ produce nanocrystals with $d=4.2-4.9 \mathrm{~nm}$ regardless of the aminophosphine used, including when a partial yield of InP is obtained. Larger sizes (up to $7.8 \mathrm{~nm}$ ) are obtained at higher temperature and when $\mathrm{InCl}_{3}$ is used. We chose $\mathrm{InI}_{3}$ for more detailed kinetics studies because of its tendency to produce smaller InP nanocrystals, which provided more room to grow larger sizes using less reactive precursors (i.e., 1-5).

InP nanocrystals with similarly narrow optical features are obtained in all reactions described herein. Although no meaningful PL is observed until a $\mathrm{ZnSe}$ shell is deposited (Figure S4), the half-width at half maximum (hwhm) of the lowest energy optical absorption feature can be compared with previously reported values (Figure S6). ${ }^{27}$ The hwhm values $(26-50 \pm 2 \mathrm{~nm})$ are equivalent to or narrower than the original report when starting from $\mathrm{InI}_{3}, \mathrm{InCl}_{3}$, a variety of aminophosphines, and various reaction temperatures (Figure S6). Narrow size distributions $(\sigma=9-14 \%)$ were confirmed using transmission electron microscopy (Figure S3). We conclude that syntheses beginning from $1-5$ and $\mathrm{P}\left(\mathrm{NMe}_{2}\right)_{3}$ produce narrow size distributions that are equivalent to the original $\operatorname{InX}_{3} / \mathrm{P}\left(\mathrm{NR}_{2}\right)_{3}$ report. The insensitivity of the absorption linewidth to the precursor used supports a precursor conversion reaction that is orthogonal to the crystallization steps. ${ }^{38,39}$ Finally, a recent study has shown that trace water improves the size distribution obtained from InX $\mathrm{X}_{3} / \mathrm{P}\left(\mathrm{NR}_{2}\right)_{3}$, a variable not explored in our work. ${ }^{40}$

The kinetics of InP formation is monitored by measuring the optical absorption $(\lambda=413 \mathrm{~nm})$ of timed aliquots. ${ }^{27}$ Although large cluster intermediates $\left(>[\mathrm{InP}]_{20}\right)$ could, in principle, contribute to the absorption at this wavelength, no spectroscopic signatures of clusters were observed herein nor has any evidence for InP clusters been reported for syntheses conducted with $\operatorname{InX} \mathrm{X}_{3} / \mathrm{P}\left(\mathrm{NR}_{2}\right)_{3}$. Several experiments were performed to test whether persistent cluster intermediates complicate our kinetics measurements (see the Supporting Information): (1) kinetics were measured using another size independent extinction coefficient $(\lambda=310 \mathrm{~nm})^{41}$ where InP clusters are known to absorb. These kinetics match those measured at $\lambda=413 \mathrm{~nm}$ throughout the reaction. This strongly suggests that any cluster intermediates are minor species. (2) Clusters could not be separated from aliquots following purification by precipitation; a minor $(\sim 10 \%)$ reduction in the ratio of the excitonic absorbance maximum and the absorbance at $413 \mathrm{~nm}$ is observed that may be caused by scattering or the absorbance of organic contaminants. (3) A mass balance was performed by comparing quantitative ${ }^{31} \mathrm{P}$ NMR measurements of precursors, intermediates, and byproducts, with the InP yield measured by ultraviolet-visible (UV-vis) absorption spectroscopy. These measurements account for $>90 \pm 10 \%$ of all phosphorus in the reaction mixture. When considering mass losses upon injection $(\sim 5-10 \%)$, we conclude that the majority of phosphorus is observed using NMR spectroscopy and UV-vis absorption measurements. These experiments all indicate that clusters are minor components of our reaction mixture and do not meaningfully influence the absorption of aliquots at $413 \mathrm{~nm}$. Moreover, any small changes in the kinetics caused by the presence of clusters cannot explain the magnitude of changes in the absorption over time nor the differences between precursors reported herein. We conclude that the absorption measurements performed here selectively monitor the yield of InP nanocrystals (within $~ 10 \%$ ) and are not meaningfully influenced by cluster intermediates.

At $180^{\circ} \mathrm{C}$, the least reactive precursors $(2,4$, and 5 ) achieve partial yield over the course of an hour, while more reactive compounds reach full conversion in under an hour (Figure 2). The rate of conversion and the yield from less reactive precursors increase at higher temperatures, often reaching $100 \%$ yield as measured by UV-vis. However, the volatility of some precursors and conversion byproducts lead to some variability that is discussed in the Supporting Information.

At the reaction temperature, the aminophosphines (1-5) transaminate with the oleylamine solvent, eventually leading to the tetrakis oleylaminophosphonium coproduct (Figures 1B and S9). These species are consistent with a conversion mechanism where a tris oleylaminophosphine (6) intermediate formed by transamination undergoes redox disproportionation to form InP, as has been elucidated for the conversion of $\mathrm{P}\left(\mathrm{NMe}_{2}\right)_{3}$ previously. ${ }^{22}$ A relatively large amount of $6(\sim 50 \%)$ is visible in the ${ }^{31} \mathrm{P}$ NMR spectrum of aliquots when more reactive precursors (1) are used, while trace amounts of 6 are observed when more sluggish precursors (2-5) are used (Figures $1 \mathrm{~B}$ and $\mathrm{S} 10$ ). These observations suggest that ethylenediamines reduce the precursor reactivity by inhibiting the formation of $\mathbf{6}$, according to Scheme 3. Relative transamination equilibrium constants $\left(K_{\mathrm{eq}}{ }^{\text {rel }}\right)$ were measured by heating ethylenediamines with $\mathbf{1}$ in oleylamine and monitoring the ratio of ${ }^{31} \mathrm{P}$ NMR signals for each (Figure

Scheme 3. Proposed Competitive Transamination Preceding Conversion to $[\mathrm{InP}]_{i}$

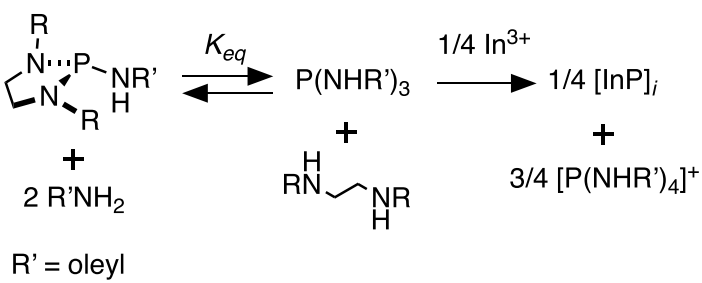


S12). These competition experiments verified that the affinity of ethylenediamine for phosphorus (o-tol $<i$-Pr $<\mathrm{Ph} \ll n$ octyl $\approx \mathrm{Bn})$ parallels the relative aminophosphine precursor reactivity. We conclude that the ethylenediamines inhibit the formation of $\mathbf{6}$ and thereby slow the conversion kinetics.

To further test this hypothesis, we measured the kinetics of InP formation from $\mathrm{P}\left(\mathrm{NMe}_{2}\right)_{3}$ in the presence of added ethylenediamines. At the reaction temperature, transamination with the added ethylenediamines occurs prior to InP formation, as could be observed with ${ }^{31} \mathrm{P}$ NMR spectroscopy. Increasing the amount of added $N, N^{\prime}$-diphenylethylenediamine and $N, N^{\prime}$-di-iso-propylethylenediamine to more than 1 diamine/phosphorus slows the kinetics of InP formation; additional equivalents lower $Q_{0}$ below their respective phosphines (2 and 3) (Figures 3 and S13). Added N,N'-di-

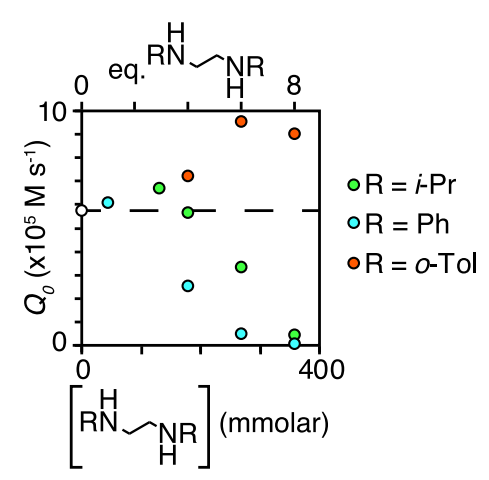

Figure 3. $Q_{0}$ for the reaction of $\mathrm{P}\left(\mathrm{NMe}_{2}\right)_{3}$ in the presence of varying concentrations (i.e., equiv/indium) of ethylenediamines at $180^{\circ} \mathrm{C}$. The $Q_{0}$ value for the conversion of $\mathrm{P}\left(\mathrm{NMe}_{2}\right)_{3}$ without additional diamine is shown by the empty circle and dashed line for reference.

$o$-tolylethylenediamine, on the other hand, slightly increases the reactivity relative to $\mathrm{P}\left(\mathrm{NMe}_{2}\right)_{3}$ alone (see the Discussion section below). Unsurprisingly the effect of the ethylenediamines on the relative reactivity of these mixtures is consistent with the relative reactivities of cyclicaminophosphines $\mathbf{1 - 5}$. With the exception of the $o$-tolyl derivative, we conclude that the ethylenediamines compete with oleylamine for phosphorus, inhibiting the formation of 6 and slowing the conversion reaction.

\section{DISCUSSION}

The relative reactivity of the aminophosphines can be explained by a transamination equilibrium between the parent amino substituents and oleylamine, as shown in Scheme 3. This pre-equilibrium controls the concentration of the reactive intermediate, 6, which then undergoes rate determining disproportionation. This explanation is consistent with our observations that the most reactive aminophosphines produce the highest amounts of $\mathbf{6}$ in NMR spectra of aliquots and that added ethylenediamine inhibits the conversion reactivity. The steady decrease in reaction rate on adding increasing equivalents (0.25-2 diamine/phosphorus) of $N, N^{\prime}$-di-isopropyl and $N, N^{\prime}$-di-phenyl ethylenediamines to reactions with $\mathrm{P}\left(\mathrm{NMe}_{2}\right)_{3}$ supports a rapid and reversible pre-equilibrium preceding the rate determining conversion step.

The substituent effects on the conversion reactivity are also consistent with the pre-equilibrium formation of $\mathbf{6}$ prior to the rate determining step. Amino substituents with greater basicity and lower steric profile compete most effectively with oleylamine for phosphorus, reducing the concentration of 6 . This explains why the aryl derivatives are more reactive compared to the more basic aliphatic derivatives and why the sterically bulky $o$-tolyl (1) derivative is more reactive than the phenyl (2) analogue. Likewise, it explains why the bulkier isopropyl (3) derivative is more reactive than the benzyl (4) or $n$ alkyl (5) analogues. Moreover, the similarity of the $o$-tolyl derivative (1) and $\mathrm{P}\left(\mathrm{NMe}_{2}\right)_{3}$ implies that the sterically bulky $o$-tolyl substituents destabilize the five-membered ring, making it equally reactive toward transamination as the acyclic $\mathrm{P}\left(\mathrm{NMe}_{2}\right)_{3} .4$ and 5 combine high basicity and a low steric profile, leading to the lowest concentration of $\mathbf{6}$ and the slowest conversion reactivity. The trends also argue against an alternative mechanism where the parent aminophosphines (rather than 6) undergo redox disproportionation prior to transamination. Such a reaction pathway might be expected to be faster when more reducing alkyl derivatives are used, in contrast with the trend in Figure 2B. We conclude that the relative reactivity of the aminophosphines is governed by the magnitude of the pre-equilibrium constant $\left(K_{\mathrm{eq}}\right)$ depicted in Scheme 3.

Adding $N, N^{\prime}$-di-o-tolylethylenediamine to reactions with $\mathrm{P}\left(\mathrm{NMe}_{2}\right)_{3}$ slightly speeds the reaction, as shown in Figure 3. This suggests a parallel conversion of $\mathbf{1}$ directly to InP or a spurious side reaction caused by the $o$-tolyl substituents. Syntheses conducted with 1 also produce slightly broader optical spectra and a small but steady decrease in absorbance at $413 \mathrm{~nm}$ at long reaction times; both support minor undesirable side reactions when $\mathbf{1}$ is used. The weak benzylic $\mathrm{C}-\mathrm{H}$ bonds and the instability of aryl-substituted ethylenediamines above $250{ }^{\circ} \mathrm{C}$ also support this hypothesis. Without more detailed analysis, it is unclear whether the diamines have other effects on the reaction (e.g., chelation to indium) that affects the kinetics or yield.

The $15 \times$ range of $Q_{0}$ provided by $1-5$ has a negligible impact on the final nanocrystal size at $180{ }^{\circ} \mathrm{C}$. Nanocrystals with $d=4.2-4.9 \mathrm{~nm}$ are isolated from all aminophosphines tested, including slowly reacting precursors such as $\mathbf{4}$ that only achieve $\sim 25 \%$ yield over an hour at this low temperature. The latter observation suggests that the extent of nucleation and the InP yield are related, a finding that is inconsistent with a burst of nucleation at early times.

At higher temperatures, larger nanocrystals are obtained whose final size can be adjusted by the precursor reactivity. Plotting the final nanocrystal volume versus $Q_{0}$ at several reaction temperatures demonstrates that the extent of nucleation becomes more sensitive to the precursor reactivity as the reaction temperature is increased (Figure 4). Note that the nanocrystal sizes/volumes shown in Figure 4 are underestimated at large sizes where the shape becomes spherical rather than tetrahedral. The underestimation is an artifact of the sizing method described in the Experimental Section. Thus, the influence of the reaction temperature on the extent of nucleation is more pronounced than is already clearly visible in Figure 4. This assumption only strengthens the mechanistic findings described below.

Our results can be explained using the nucleation mass balance model formalized by Sugimoto and described in previous studies on $\mathrm{PbS}, \mathrm{PbSe}, \mathrm{CdS}, \mathrm{CdSe}, \mathrm{AgCl}$, and AgBr. ${ }^{13-15,17,42-46}$ This model explains how the nucleation and the growth processes compete with one another for supersaturated solutes (Scheme 4). The model defines nucleation as the formation of "stable nuclei", that is, crystals 


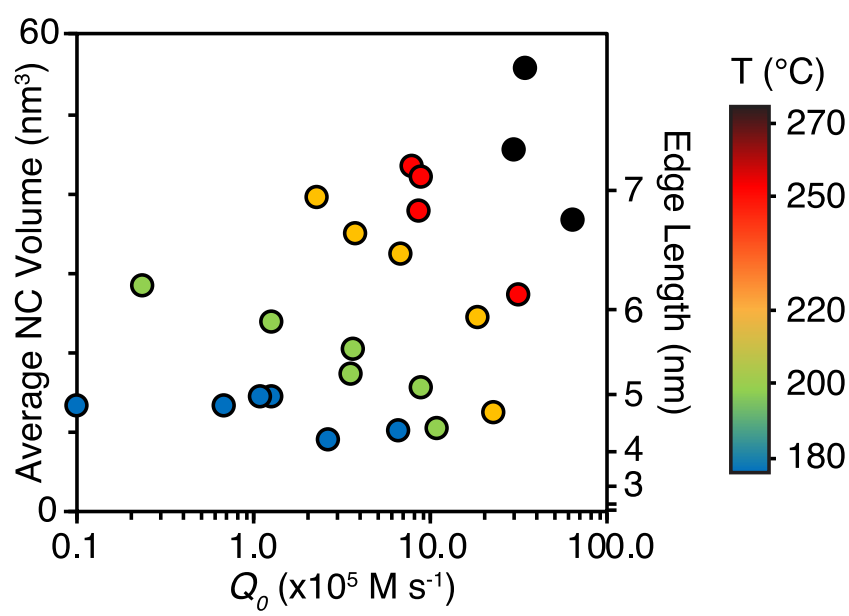

Figure 4. Plot of the final InP NC volume $v s Q_{0}$ for five different InPforming conditions at $180,200,220,250$, and $270{ }^{\circ} \mathrm{C}$. At higher temperatures, the growth rate increases and addition of monomers to the nanocrystal surface consumes a greater fraction of the solute.

Scheme 4. Nucleation Mass Balance Showing the Production and Consumption of Solutes by Nucleation and Growth

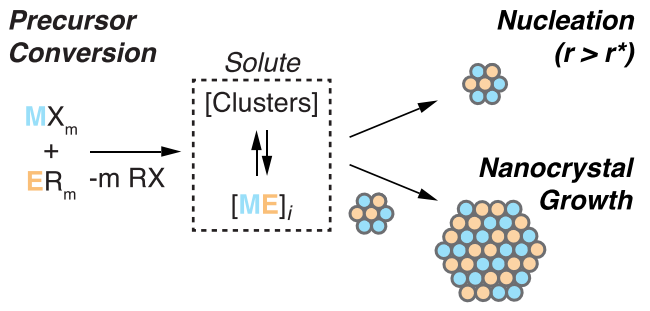

that do not redissolve but grow to their final size. Likewise, growth is the sum of all processes that deposit monomers on nanocrystals equal to or greater than the radius of stable nuclei (i.e., $r>r^{*}$ ). The rate can be expressed as the average rate of change in the number of units per nanocrystal and includes the consumption of unstable nuclei, clusters, oligomers, and monomers. The model does not, however, consider mechanisms where "stable nuclei" and growing nanocrystals aggregate or Ostwald-ripen. These processes do not appear to be important under our conditions as the concentration of nanocrystals steadily increases during all kinetics measurements in this study (see below). If such mechanisms were occurring in parallel, they would only dampen the magnitude of the trends observed herein, strengthening the mechanistic conclusions reached below.

The mass balance framework illustrated in Scheme 4 leads to an inverse relationship between the rate of crystal growth and the number of nanocrystals, provided that the nucleation and growth kinetics are limited by precursor conversion. Under these conditions, the steady-state monomer concentration is determined by the number of nanocrystals and the precursor reactivity, and tuning the precursor conversion kinetics will change the extent of nucleation and the final size.

However, the consistent final size obtained at low temperature suggests that growth kinetics slow as the nanocrystal reaches $d=4 \mathrm{~nm}$. This is consistent with a mechanism that is limited by growth kinetics, rather than precursor conversion. Herein lies the value of the aminophosphine library: by reducing the conversion reactivity, we can access precursor conversion limited kinetics at high temperature.

A similar reluctance to grow beyond a few nanometers has also been reported in syntheses of $\operatorname{InP}$ from $\operatorname{In}\left(\mathrm{O}_{2} \mathrm{CR}\right)_{3}$ and $\mathrm{P}\left(\mathrm{SiMe}_{3}\right)_{3}{ }^{1,8-10,47-49}$ Although the final size in these studies is different from the present one, very different precursors, kinetics, surfactants, and reaction temperatures can be expected to cause significant differences in the growth dynamics. Moreover, the formation of oxide byproducts is thought to play an important role in these examples. ${ }^{50}$ Others have shown that clusters persist in syntheses from $\operatorname{In}\left(\mathrm{O}_{2} \mathrm{CR}\right)_{3}$ and $\mathrm{P}\left(\mathrm{SiMe}_{3}\right)_{3}$ at temperatures below $150{ }^{\circ} \mathrm{C}$, much lower temperatures than those used here. ${ }^{20}$ At higher temperatures, these clusters ripen into larger nanocrystals. Although mass spectrometry has identified clusters in synthesis mixtures at nearly $300{ }^{\circ} \mathrm{C}$, their chemical composition, abundance, and lifetime in the reaction mixture are unknown and they may be a minor component of the available solute. ${ }^{41}$ We conclude that the ripening of clusters into nanocrystals is consistent with the mechanism shown in Scheme 4, where clusters are a form of the solute that is consumed by growth.

A plot of the nanocrystal concentration versus time allows the length of the nucleation phase to be estimated (Figure $5 \mathrm{~A}, \mathrm{~B})$. In all reactions studied here, nucleation continues over

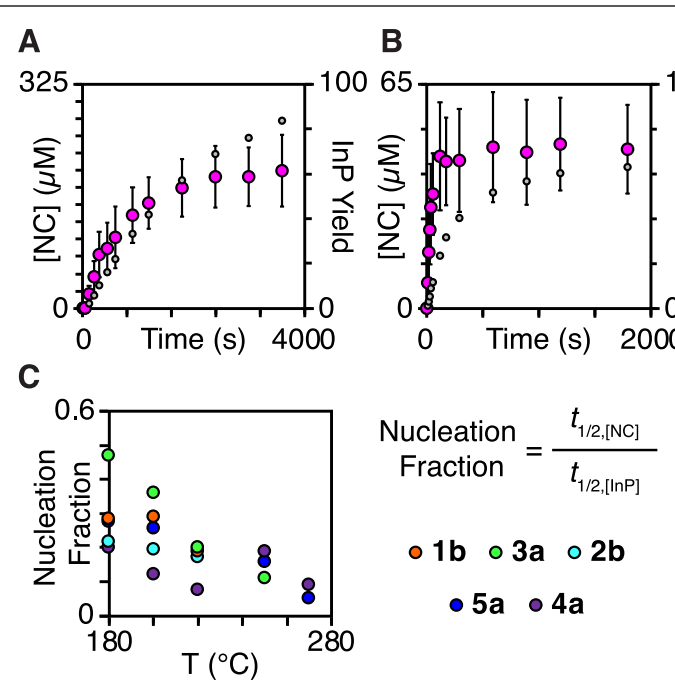

Figure 5. Plot of nanocrystal concentration (pink) and InP yield (gray) $v s$ time for reactions of $3 \mathrm{a}$ at $180^{\circ} \mathrm{C}$ (A) and $5 \mathrm{a}$ at $250{ }^{\circ} \mathrm{C}$ (B) under InP-forming conditions. (C) Nucleation as a fraction of the total reaction time $v s$ temperature. The nucleation fraction is defined as the fraction of [nanocrystal] and InP yield half-lives $\left(t_{1 / 2,[\mathrm{NC}]} /\right.$ $\left.t_{1 / 2, \text { InP }}\right)$. These values were extracted by fitting InP yield and [nanocrystal] vs time plots to a single exponential function $(y=A$ $\left.\mathrm{e}^{-k t}\right)$, the latter of which is displayed in Section 6 of the Supporting Information.

a significant percentage of the total reaction time (Section 6 of the Supporting Information). Interestingly, the length of the nucleation phase depends on temperature. At low temperature, where $4.2-4.9 \mathrm{~nm}$ nanocrystals are consistently obtained (Figure 5A), the number of nanocrystals steadily increases throughout the synthesis (nucleation half-life or $t_{1 / 2,[\mathrm{NC}]} \approx 500$ s), while at high temperatures (Figure $5 \mathrm{~B}$ ), the nucleation reaches completion at earlier times $\left(t_{1 / 2,[\mathrm{NC}]} \approx 30 \mathrm{~s}\right)$ and is followed by growth. The steady eightfold increase in the concentration of nanocrystals plotted in Figure 5A strongly supports the slow continuous nucleation under these 
conditions. In all cases, nucleation persists for many minutes to hours and often for more than $50 \%$ of the total reaction time.

The percentage of the reaction over which nucleation occurs can be estimated from $t_{1 / 2,[\mathrm{NC}]}$ and the time over which the InP yield reaches $50 \%$ or the reaction half-life $\left(t_{1 / 2,[\operatorname{InP}]}\right)$; we refer to their ratio as the "nucleation fraction" and use this value to estimate the relative duration of the nucleation phase at different temperatures. These values are plotted at several temperatures for all precursor combinations studied here in Figure 5C. At low temperatures, nucleation continues over up to half of the total reaction, while it reaches completion in the first $10 \%$ of the reaction at higher temperatures. We conclude that nucleation occurs in more of a "burst" at high temperatures, while lower temperatures support slow continuous nucleation.

Given the long nucleation times observed here, it is perhaps surprising that relatively narrow size distributions are obtained. The canonical picture of monodisperse nanoparticle formation relies on a rapid "burst" of nucleation that is separate from growth, as famously attributed to LaMer. ${ }^{16,51,52}$ In this picture, the duration of the nucleation burst is thought to be related to the size distribution. The distributions obtained here, as estimated from the hwhm of the excitonic feature in the absorption spectrum, are plotted versus the nanocrystal size in Figure S6. Comparing these values versus temperature shows that improved separation between nucleation and growth does not correlate with narrower optical absorption features.

Although a detailed analysis of the size distribution is beyond the scope of this study, it is clear that a form of size focusing is required to explain our results. Previous work on size distribution focusing describes how such a mechanism can be a consequence of diffusion limited growth kinetics. ${ }^{53-55}$ However, neither the highly cited work of Peng and Alivisatos nor subsequent papers consider the broad, size dependent linewidths of single nanoparticles when estimating the size distribution evolution with time. Recent studies on lead and cadmium chalcogenide nanocrystals have shown that the absorption and PL linewidth of a single nanocrystal are intrinsically broadened (accounting for the majority of the total width in monodisperse samples) and that the broadening is strongly size dependent. ${ }^{13-15}$ Extracting a nanocrystal size distribution from the PL linewidth is therefore incorrect if the intrinsic width of a single size is not taken into account. Treating the intrinsic single nanocrystal absorption/PL linewidth as being much smaller than the broadening from polydispersity will incorrectly lead to the conclusion that the size distribution undergoes focusing during growth. Moreover, this analysis assumes that all nanocrystals are produced in a burst at early times, rather than a more complex distribution that results from concurrent nucleation and growth over the majority of the synthesis. These oversights invalidate previous claims of size distribution focusing based on analysis of the optical spectrum.

Likewise, a diffusion limited mechanism cannot explain our results including (1) the sluggish growth of nanocrystals beyond $4.9 \mathrm{~nm}$ at $180^{\circ} \mathrm{C},(2)$ a nucleation process that is more rapid than growth beyond $4.9 \mathrm{~nm}$ over more than 1 order of magnitude of solute supply kinetics, and (3) thermally activated growth kinetics. Diffusion in liquids is not thermally activated. ${ }^{56}$ This leaves the conclusion that the polydispersities obtained here are the result of size dependent attachment kinetics, a mechanism of size distribution focusing with an unknown origin.
Although theoretical work on size dependent attachment kinetics is uncommon, Finke and co-workers have recently demonstrated a computational framework for this mechanism using population balance modeling. ${ }^{57}$ In addition, a computational study of InP nanocrystal formation by Kulik and coworkers showed that the distribution of indium atoms on carboxylate-bound InP nanocrystal surfaces can dictate the energetics of growth, which slows as the size increases. ${ }^{58,59}$ Likewise, it is well known that surfactants have a significant influence on the final nanocrystal size and growth kinetics in hot-injection syntheses and ripening experiments, including recent work regarding the role of trace water on the size distribution. ${ }^{17,37,40,60-64}$ It is therefore of great interest to probe the intrinsic reactivity of nanocrystal surfaces toward monomer attachment and how this reactivity is influenced by size, shape, and surface ligands. New perspectives on this reactivity can lead to improved mechanisms of size distribution control.

Finally, it is interesting to consider whether the lack of a nucleation burst and size dependent growth kinetics may be relevant in other colloidal nanocrystal syntheses. In particular, this mechanism could explain the recent report of narrower size distributions obtained using a "heat-up" method. ${ }^{8}$ Low temperatures at early reaction times could produce a narrow distribution of small nanocrystals that then grow as the temperature increases, effectively separating the nucleation and growth stages. A related study by the same authors reports the slow injection of InP solute into a solution of seed crystals at low temperature. 9 These conditions did not increase the seed size which was hypothesized to be the result of continuous nucleation. Both observations point to a mechanism where continuous nucleation and size dependent growth kinetics are operative in InP syntheses from indium carboxylates and (TMS) ${ }_{3} P .{ }^{19,20,65}$ Interestingly, a size dependent growth rate can explain the selective formation of atomically precise, pyramidal CdSe clusters. ${ }^{60}$ A quantized growth mechanism, where a small pyramid grows to the next larger size but does not grow further, requires that monomers selectively attach to small rather than large clusters.

Continuous nucleation has also been observed in syntheses of CdSe nanocrystals monitored in situ using small angle X-ray scattering. ${ }^{66}$ However, this study and other studies that analyze the temporal evolution of the $\mathrm{CdSe}$ and $\mathrm{PbS}$ nanocrystal concentration typically attribute the size distribution to a burst of nucleation, as depicted by LaMer. It should be noted, however, that measurements of the nanocrystal concentration are challenging at length scales less than $4 \mathrm{~nm}$, where precise measurements of the nanocrystal shape, density, and stoichiometry are required to determine the number of monomer units per nanocrystal. ${ }^{67}$ This weakness is especially true in syntheses that traverse a wide range of sizes. In the present work, the average size evolves over a relatively small range, reducing this source of uncertainty.

Finally, size dependent growth kinetics can help explain the formation of a second population of nanocrystals during deposition of a shell material onto a core nanocrystal (e.g., CdS onto CdSe cores). If the rate of growth slows as the shell thickens, it can lead to monomer supersaturation and homogeneous nucleation. This observation helps explain the importance of high-temperature conditions used in the synthesis of core-shell nanocrystals with thick shells and recent work on the synthesis of $\mathrm{InP} / \mathrm{ZnSe}$ nanocrystals. ${ }^{3}$ 


\section{CONCLUSIONS}

The mechanistic investigations reported here benefit from relatively slow precursor conversion kinetics at both low and high temperatures. Higher temperatures increase the rate of growth inducing precursor conversion limited kinetics, much like syntheses of $\mathrm{PbS}, \mathrm{PbSe}, \mathrm{CdS}, \mathrm{CdSe}, \mathrm{AgCl}$, and $\mathrm{AgBr}$ nanocrystals. Under these conditions, the cyclic aminophosphine precursor reactivity tunes the number of InP nanocrystals and their final size. All reactions studied here undergo slow, continuous nucleation concurrent with growth yet achieve narrow size distributions. To explain these results, the nanoparticle growth rate must be size dependent, a mechanism that appears to be determined by the kinetics of monomer attachment, rather than diffusion limitations. These mechanistic proposals provide an experimentally validated alternative to the LaMer model.

\section{EXPERIMENTAL SECTION}

General Methods. All manipulations were conducted using standard air-free techniques unless otherwise specified. Acetone ( $\geq 99.5 \%)$, dichloromethane ( $\geq 99.5 \%$, contains $40-150 \mathrm{ppm}$ amylene as a stabilizer), dimethylformamide (ACS reagent, $\geq 99.8 \%$ ), lithium aluminum hydride (powder, reagent grade, 95\%), octanoic acid (99\%), sodium hydroxide (anhydrous, free-flowing, pellets ACS reagent, $\geq 97 \%)$, tetrahydrofuran ( $\geq 99.0 \%$, contains $250 \mathrm{ppm} \mathrm{BHT}$ as inhibitor), toluene $(\geq 99.5 \%)$, and triethylamine $(\geq 99 \%)$ were obtained from Sigma-Aldrich and used without further purification for manipulations in air. Indium(III) chloride (99.999\%, anhydrous), indium(III) iodide (99.999\%), tri- $n$-octylphosphine (97\%), and zinc(II) chloride ( $\geq 97$, anhydrous) were obtained from Strem Chemicals and used without further purification. $N, N^{\prime}$-diphenylethylenediamine (98\%), octadecylamine $(\geq 99.0 \%)$, selenium (powder, -100 mesh, $99.99 \%$, trace metal basis), and zinc stearate (technical grade, $65 \%$ ) were purchased from Sigma-Aldrich and used without further purification. $N, N^{\prime}$-di(o-tolyl)ethylenediamine (98\%) was purchased from Alfa Aesar and used without further purification. Chloroform- $d(99.8 \%)$ and benzene- $d_{6}(99.5 \%)$ were obtained from Cambridge Isotopes and stored in a glovebox over $3 \AA$ molecular sieves. Dichloromethane ( $\geq 99.5 \%$, contains $40-150 \mathrm{ppm}$ amylene as a stabilizer), diethyl ether ( $\geq 99.9 \%$, inhibitor-free), and tetrahydrofuran ( $\geq 99.0 \%$, contains $250 \mathrm{ppm} \mathrm{BHT} \mathrm{as} \mathrm{an} \mathrm{inhibitor)} \mathrm{were}$ obtained from Sigma-Aldrich, degassed, dried in a column packed with activated alumina, and stored in a glovebox over $3 \AA$ molecular sieves for $24 \mathrm{~h}$ prior to use. Diethylamine ( $\geq 99.5 \%)$, triethylamine ( $\geq 99 \%), N, N^{\prime}$-dibenzylethylenediamine (97\%), $N, N^{\prime}$-diisopropylethylenediamine (99\%), octadecene (technical grade, 90\%), tetraethylene glycol dimethyl ether ( $\geq 99 \%)$, trioctylamine (98\%), tris(diethylamino)phosphine (97\%), and tris(dimethylamino)phosphine (97\%) were obtained from Sigma-Aldrich, stirred over calcium hydride overnight, distilled, and stored in a glovebox.

Oleylamine (technical grade, 70\%) was obtained from SigmaAldrich, stirred over calcium hydride overnight, and fractionally distilled to remove lower boiling fractions. ${ }^{68}$ The desired fraction was collected and stored in a glovebox. Oxalyl chloride $(\geq 99 \%)$ and phosphorus trichloride (99.999\%, trace metal basis) were obtained from Sigma-Aldrich, degassed by the freeze-pump-thaw method, distilled, and stored in a Strauss flask under argon outside of the glovebox. Tri- $n$-octylphosphine oxide (99\%) was obtained from Strem Chemicals and recrystallized.

Instrumentation. UV-vis spectra were obtained using a PerkinElmer Lambda 950 spectrophotometer equipped with deuterium and halogen lamps. PL measurements were performed using a Fluoromax 4 from Horiba Scientific. Powder X-ray diffraction patterns were measured using a PANalytical X'Pert powder X-ray diffractometer. Transmission electron microscopy and scanning transmission electron microscopy images were collected using an
FEI Talos F200X. NMR spectroscopy was performed using Bruker 400 and $500 \mathrm{MHz}$ spectrometers.

Synthesis of Cyclic Trisaminophosphines (1-5). $N, N^{\prime}$ Dioctylethylenediamine was synthesized according to a published procedure. ${ }^{69}$ Purity was confirmed via ${ }^{1} \mathrm{H}$ and ${ }^{13} \mathrm{C}$ NMR spectroscopy. ${ }^{1} \mathrm{H}$ NMR $\left(500 \mathrm{MHz}, \mathrm{C}_{6} \mathrm{D}_{6}\right): \delta 0.90(\mathrm{t}, 8 \mathrm{H}), 1.28(\mathrm{~m}, 20 \mathrm{H})$, 1.45 (quin, 4H), $2.56(\mathrm{t}, 4 \mathrm{H}), 2.66(\mathrm{~s}, 4 \mathrm{H}) .{ }^{13} \mathrm{C}\left\{{ }^{1} \mathrm{H}\right\}$ NMR $(125$ $\left.\mathrm{MHz}, \mathrm{C}_{6} \mathrm{D}_{6}\right): \delta 14.00(\mathrm{~s}), 22.74(\mathrm{~s}), 27.50(\mathrm{~s}), 29.45(\mathrm{~s}), 29.70(\mathrm{~s})$, $30.54(\mathrm{~s}), 31.93(\mathrm{~s}), 49.91(\mathrm{~s}), 50.10(\mathrm{~s})$.

2-Chloro-1,3-di(2-methylphenyl)-1,3,2-diazaphospholidine. $N, N^{\prime}$-Di(2-methylphenyl)ethylenediamine (6.004 g, $25.00 \mathrm{mmol}$ ), triethylamine $(17.675 \mathrm{~g}, 175.00 \mathrm{mmol})$, and dichloromethane (200 $\mathrm{mL}$ ) are loaded into a Schlenk flask. The mixture is cooled to $0{ }^{\circ} \mathrm{C}$ on a Schlenk line. Phosphorus trichloride $(2.30 \mathrm{~mL}, 26.3 \mathrm{mmol})$ is added dropwise and allowed to stir for $1 \mathrm{~h}$. Precipitation of a white solid is observed immediately upon addition. The reaction is allowed to return to room temperature for $1 \mathrm{~h}$, and volatiles are removed in vacuo. The residue is dissolved in THF and filtered. Volatiles are removed from the filtrate, and the resulting solid was recrystallized in THF at $-40{ }^{\circ} \mathrm{C}$ to yield a pale yellow solid. Yield $6.277 \mathrm{~g}(83 \%)$. ${ }^{31} \mathrm{P}\left\{{ }^{1} \mathrm{H}\right\}$ NMR $\left(202 \mathrm{MHz}, \mathrm{CDCl}_{3}\right): \delta 148.27 .{ }^{1} \mathrm{H}$ NMR $(500 \mathrm{MHz}$, $\left.\mathrm{CDCl}_{3}\right): \delta 2.46(\mathrm{~s}, 6 \mathrm{H}), 3.72(\mathrm{~s}, 2 \mathrm{H}), 4.12(\mathrm{~s}, 2 \mathrm{H}), 7.20(\mathrm{t}, 2 \mathrm{H}), 7.28$ (m, 4H), $7.46(\mathrm{~d}, 2 \mathrm{H}),{ }^{13} \mathrm{C}\left\{{ }^{1} \mathrm{H}\right\}$ NMR $\left(125 \mathrm{MHz}, \mathrm{CDCl}_{3}\right): \delta 18.64$ (d), 52.03 (d), 126.28 (d) 126.46 (d), 127.02 (d), 131.26 (s). Anal. Calcd for $\mathrm{C}_{16} \mathrm{H}_{18} \mathrm{ClN}_{2} \mathrm{P}$ : C, 63.06; H, 5.95; N, 9.19. Found: C, 62.69; $\mathrm{H}, 6.18$; N, 8.99. MS (ASAP) $m / z$ : calcd for $\left[\mathrm{C}_{16} \mathrm{H}_{18} \mathrm{~N}_{2} \mathrm{PCl}+\mathrm{H}^{+}\right]$, 305.0974; found, 305.0958 .

2-Chloro-1,3-dibenzyl-1,3,2-diazaphospholidine. The abovementioned procedure was followed using $N, N^{\prime}$-dibenzylethylenediamine $(3.004 \mathrm{~g}, 12.5 \mathrm{mmol})$, triethylamine $(7.575 \mathrm{~g}, 75.0 \mathrm{mmol})$, phosphorus trichloride $(1.15 \mathrm{~mL}, 13.1 \mathrm{mmol})$, and diethyl ether $(100 \mathrm{~mL})$. The crude product is a dark orange liquid used without further purification. Yield $3.076 \mathrm{~g}(81 \%) .{ }^{31} \mathrm{P}\left\{{ }^{1} \mathrm{H}\right\} \mathrm{NMR}(202 \mathrm{MHz}$, $\mathrm{CDCl}_{3}$ ): $\delta$ 167.83. ${ }^{1} \mathrm{H}$ NMR $\left(500 \mathrm{MHz}, \mathrm{CDCl}_{3}\right): \delta 3.29$ (d, $\left.4 \mathrm{H}\right), 4.29$ (s, 4H), $7.36(\mathrm{~m}, 2 \mathrm{H}), 7.44(\mathrm{~m}, 8 \mathrm{H}) .{ }^{13} \mathrm{C}\left\{{ }^{1} \mathrm{H}\right\}$ NMR $(125 \mathrm{MHz}$ $\left.\mathrm{CDCl}_{3}\right): \delta 50.05$ (d), 51.47 (d), 127.81 (s), 128.65 (d). Anal. Calcd for $\mathrm{C}_{16} \mathrm{H}_{18} \mathrm{~N}_{2} \mathrm{PCl}$ : C, 63.06; $\mathrm{H}, 5.95 ; \mathrm{N}, 9.19$. Found: C, 62.78; H, 6.25; N, 9.22. MS (ASAP) $m / z$ : calcd for $\left[\mathrm{C}_{16} \mathrm{H}_{18} \mathrm{~N}_{2} \mathrm{PCl}+\mathrm{H}^{+}\right]$, 305.0974; found, 305.0978 .

2-Chloro-1,3-dioctyl-1,3,2-diazaphospholidine. The abovementioned procedure was followed using $N, N^{\prime}$-dioctylethylenediamine $(1.778 \mathrm{~g}, 6.300 \mathrm{mmol})$, triethylamine $(3.788 \mathrm{~g}, 37.50 \mathrm{mmol})$, phosphorus trichloride $(0.57 \mathrm{~mL}, 6.6 \mathrm{mmol})$, and THF $(50 \mathrm{~mL})$. The crude product is a pale yellow liquid used without further purification. Yield $1.974 \mathrm{~g}(91 \%) .{ }^{31} \mathrm{P}\left\{{ }^{1} \mathrm{H}\right\} \mathrm{NMR}\left(202 \mathrm{MHz}, \mathrm{C}_{6} \mathrm{D}_{6}\right): \delta$ 163.29. ${ }^{1} \mathrm{H}$ NMR $\left(500 \mathrm{MHz}, \mathrm{C}_{6} \mathrm{D}_{6}\right): \delta 0.90(\mathrm{t}, 6 \mathrm{H}), 1.22(\mathrm{~m}, 20 \mathrm{H})$, $1.50(\mathrm{t}, 4 \mathrm{H}), 2.73(\mathrm{~m}, 2 \mathrm{H}), 2.89(\mathrm{~m}, 4 \mathrm{H}), 3.04(\mathrm{~m}, 2 \mathrm{H}) .{ }^{13} \mathrm{C}\left\{{ }^{1} \mathrm{H}\right\}$ NMR (125 MHz, $\left.\mathrm{C}_{6} \mathrm{D}_{6}\right): \delta 13.99$ (s), 22.70 (s), 27.00 (s), 28.71 (d), 29.28 (s), 31.83 (s), 47.32 (d), 49.79 (d). Anal. Calcd for $\mathrm{C}_{16} \mathrm{H}_{18} \mathrm{~N}_{2} \mathrm{PCl}$ : C, 61.96; H, 10.98; N, 8.03. Found: C, 61.73; H, 11.24; N, 8.04. MS (ASAP) $m / z$ : calcd for $\left[\mathrm{C}_{18} \mathrm{H}_{39} \mathrm{~N}_{2} \mathrm{PCl}+\mathrm{H}^{+}\right]$, 349.2539; found, 349.2518 .

2-Chloro-1,3-diphenyl-1,3,2-diazaphospholidine was synthesized according to a published procedure on a $26 \mathrm{mmol}$ scale. ${ }^{70}$ Purity is confirmed via ${ }^{31} \mathrm{P},{ }^{1} \mathrm{H}$, and ${ }^{13} \mathrm{C}$ NMR spectroscopy. ${ }^{31} \mathrm{P}\left\{{ }^{1} \mathrm{H}\right\}$ NMR $\left(162 \mathrm{MHz}, \mathrm{CDCl}_{3}\right): \delta 137.28 .{ }^{1} \mathrm{H}$ NMR $\left(400 \mathrm{MHz}, \mathrm{CDCl}_{3}\right): \delta 4.00$ (s, 4H), $7.08(\mathrm{t}, 2 \mathrm{H}), 7.20(\mathrm{~m}, 4 \mathrm{H}), 7.39(\mathrm{t}, 4 \mathrm{H}) .{ }^{13} \mathrm{C}\left\{{ }^{1} \mathrm{H}\right\} \mathrm{NMR}$ $\left(125 \mathrm{MHz}, \mathrm{CDCl}_{3}\right): \delta 31.63(\mathrm{t}), 117.13$ (d), 122.23 (d), 129.59 (s).

2-Chloro-1,3-diisopropyl-1,3,2-diazaphospholidine was synthesized according to a published procedure on a $26 \mathrm{mmol}$ scale. ${ }^{71}$ Purity is confirmed via ${ }^{31} \mathrm{P},{ }^{1} \mathrm{H}$, and ${ }^{13} \mathrm{C}$ NMR spectroscopy. ${ }^{31} \mathrm{P}\left\{{ }^{1} \mathrm{H}\right\}$ NMR $\left(202 \mathrm{MHz}, \mathrm{CDCl}_{3}\right): \delta 169.19 .{ }^{1} \mathrm{H}$ NMR $\left(500 \mathrm{MHz}, \mathrm{CDCl}_{3}\right): \delta 1.26$ (d, 12H), 3.29 (d, 4H), $3.39(\mathrm{~m}, 2 \mathrm{H}) .{ }^{13} \mathrm{C}\left\{{ }^{1} \mathrm{H}\right\}$ NMR $(125 \mathrm{MHz}$, $\mathrm{CDCl}_{3}$ ): $\delta 22.00(\mathrm{~s}), 46.43(\mathrm{~d}), 48.44(\mathrm{~d})$.

N,N-Diethyl-1,3-di(2-methylphenyl)-1,3,2-diazaphospholidin-2amine (1a). 2-Chloro-1,3-di(2-methylphenyl)-1,3,2-diazaphospholidine $(1.106 \mathrm{~g}, 3.600 \mathrm{~mol})$, triethylamine $(485 \mathrm{~g}, 4.80 \mathrm{~mol})$, and diethyl ether $(20 \mathrm{~mL})$ are loaded into a scintillation vial. Diethylamine $(0.415 \mathrm{~mL}, 4.80 \mathrm{~mol})$ is added dropwise and allowed to stir for 20 min. Precipitation of a white solid is observed immediately upon 
injection. The solid byproduct is filtered off. The resulting pale yellow oil is used without further purification. Yield $1.087 \mathrm{~g}(88 \%) .{ }^{31} \mathrm{P}\left\{{ }^{1} \mathrm{H}\right\}$ NMR (162 MHz, $\left.\mathrm{CDCl}_{3}\right): \delta 101.10 .{ }^{1} \mathrm{H} \mathrm{NMR}\left(400 \mathrm{MHz}, \mathrm{CDCl}_{3}\right): \delta$ $0.73(\mathrm{t}, 6 \mathrm{H}), 2.48(\mathrm{~s}, 6 \mathrm{H}), 3.02(\mathrm{~m}, 4 \mathrm{H}), 3.39$ (oct, $2 \mathrm{H}), 4.03$ (sext, $2 \mathrm{H}), 7.04(\mathrm{t}, 2 \mathrm{H}), 7.20(\mathrm{~m}, 4 \mathrm{H}), 7.30(\mathrm{~d}, 2 \mathrm{H}) .{ }^{13} \mathrm{C}\left\{{ }^{1} \mathrm{H}\right\}$ NMR $(125$ $\mathrm{MHz}, \mathrm{CDCl}_{3}$ ): $\delta 14.30$ (s), 19.71 (d), 38.86 (d), 51.55 (d), 123.67 (d), 125.32 (d), 126.45 (s), 131.19 (s). Anal. Calcd for $\mathrm{C}_{20} \mathrm{H}_{28} \mathrm{~N}_{3} \mathrm{P}$ : C, 70.36; H, 8.27; N, 12.31. Found: C, 70.46; H, 8.39; N, 12.21. MS (ASAP) $m / z$ : calcd for $\left[\mathrm{C}_{20} \mathrm{H}_{28} \mathrm{~N}_{3} \mathrm{P}+\mathrm{H}^{+}\right], 342.2099$; found, 342.2104 .

N-Octadecyl-1,3-di(2-methylphenyl)-1,3,2-diazaphospholidin-2amine (1b). 2-Chloro-1,3-di(2-methylphenyl)-1,3,2-diazaphospholidine $(1.106 \mathrm{~g}, 3.6 \mathrm{mmol})$, triethylamine $(485 \mathrm{mg}, 4.80 \mathrm{mmol})$, and diethyl ether $(15 \mathrm{~mL})$ are loaded into a scintillation vial. Octadecylamine $(1.080 \mathrm{~g}, 4.000 \mathrm{mmol})$ is dissolved in diethyl ether $(5 \mathrm{~mL})$ and added dropwise and allowed to stir for $20 \mathrm{~min}$. Precipitation of a white solid is observed immediately upon injection. The solid byproduct is filtered off. Volatiles are removed from the filtrate, and the resulting solid is recrystallized in THF at $-40{ }^{\circ} \mathrm{C}$ to yield a pale yellow solid. Yield $1.785 \mathrm{~g}(91 \%) .{ }^{31} \mathrm{P}\left\{{ }^{1} \mathrm{H}\right\}$ NMR (202 $\left.\mathrm{MHz}, \mathrm{CDCl}_{3}\right): \delta 90.60 .{ }^{1} \mathrm{H} \mathrm{NMR}\left(500 \mathrm{MHz}, \mathrm{CDCl}_{3}\right): \delta 0.91(\mathrm{t}, 3 \mathrm{H})$, $1.28(\mathrm{~m}, 34 \mathrm{H}), 2.35(\mathrm{~m}, 1 \mathrm{H}), 2.47(\mathrm{~s}, 6 \mathrm{H}), 2.90$ (quin, $2 \mathrm{H}), 3.39(\mathrm{~m}$, $2 \mathrm{H}), 3.89(\mathrm{~m}, 2 \mathrm{H}), 7.05(\mathrm{t}, 2 \mathrm{H}), 7.24(\mathrm{~m}, 7 \mathrm{H}) .{ }^{13} \mathrm{C}\left\{{ }^{1} \mathrm{H}\right\}$ NMR $(125$ $\mathrm{MHz}, \mathrm{CDCl}_{3}$ ): $\delta 14.17$ (s), 19.61 (d), 22.73 (s), 26.87 (s), 29.39 (s) $29.61(\mathrm{~d}) 29.72(\mathrm{~m}), 31.96(\mathrm{~s}), 33.06$ (s), 42.00 (d), 51.00 (d), 123.85 (s), 125.21 (d), 126.52 (s), 131.15 (s). Anal. Calcd for $\mathrm{C}_{34} \mathrm{H}_{56} \mathrm{~N}_{3} \mathrm{P}: \mathrm{C}, 75.93 ; \mathrm{H}, 10.50 ; \mathrm{N}, 7.81$. Found: $\mathrm{C}, 75.89 ; \mathrm{H}, 10.63$; $\mathrm{N}, 7.82$. MS (ASAP) $m / z$ : calcd for $\left[\mathrm{C}_{34} \mathrm{H}_{57} \mathrm{~N}_{3} \mathrm{P}+\mathrm{H}^{+}\right]$, 538.4290; found, 538.4298 .

$\mathrm{N}$-tert-Butyl-1,3-di(2-methylphenyl)-1,3,2-diazaphospholidin-2amine (1c). 2-Chloro-1,3-di(2-methylphenyl)-1,3,2-diazaphospholidine $(553 \mathrm{mg}, 1.80 \mathrm{mmol})$, triethylamine $(242 \mathrm{mg}, 2.40 \mathrm{mmol})$, and THF $(10 \mathrm{~mL})$ are loaded into a scintillation vial. tert-Butylamine $(0.207 \mathrm{~mL}, 2.00 \mathrm{mmol})$ is added dropwise and allowed to stir for 20 min. Precipitation of a white solid is observed immediately upon injection. The solid byproduct is filtered off. Volatiles are removed from the filtrate, and the resulting solid is recrystallized in THF at $-40{ }^{\circ} \mathrm{C}$ to yield a pale yellow solid. Yield: $620 \mathrm{mg}(99 \%) .{ }^{31} \mathrm{P}\left\{{ }^{1} \mathrm{H}\right\}$ NMR (202 MHz, $\left.\mathrm{CDCl}_{3}\right): \delta 87.27 .{ }^{1} \mathrm{H}$ NMR (500 MHz, $\left.\mathrm{CDCl}_{3}\right): \delta$ $0.91(\mathrm{t}, 3 \mathrm{H}), 1.28(\mathrm{~m}, 34 \mathrm{H}), 2.35(\mathrm{~m}, 1 \mathrm{H}), 2.47(\mathrm{~s}, 6 \mathrm{H}), 2.90$ (quin, $2 \mathrm{H}), 3.39(\mathrm{~m}, 2 \mathrm{H}), 3.89(\mathrm{~m}, 2 \mathrm{H}), 7.05(t, 2 \mathrm{H}), 7.24(\mathrm{~m}, 7 \mathrm{H})$. ${ }^{13} \mathrm{C}\left\{{ }^{1} \mathrm{H}\right\}$ NMR (125 MHz, $\left.\mathrm{CDCl}_{3}\right): \delta 19.57$ (d), 32.78 (d), 49.79 (d), 123.48 (d), 124.75 (d), 126.39 (s), 130.90 (s). Anal. Calcd for $\mathrm{C}_{20} \mathrm{H}_{28} \mathrm{~N}_{3} \mathrm{P}: \mathrm{C}, 70.36 ; \mathrm{H}, 8.27 ; \mathrm{N}, 12.31$. Found: C, 70.11; H, 8.38; N, 12.12. MS (ASAP) $m / z$ : calcd for $\left[\mathrm{C}_{20} \mathrm{H}_{28} \mathrm{~N}_{3} \mathrm{P}+\mathrm{H}^{+}\right]$, 342.2099; found, 342.2094 .

$N, N$-Diethyl-1,3-diphenyl-1,3,2-diazaphospholidin-2-amine (2a) is prepared according to a published procedure on a $3.55 \mathrm{mmol} \mathrm{scale.}{ }^{34}$ Purity is confirmed via ${ }^{31} \mathrm{P},{ }^{1} \mathrm{H}$, and ${ }^{13} \mathrm{C}$ NMR spectroscopy. ${ }^{31} \mathrm{P}\left\{{ }^{1} \mathrm{H}\right\}$ NMR (202 MHz, $\left.\mathrm{CDCl}_{3}\right): \delta 95.24 .{ }^{1} \mathrm{H} \mathrm{NMR}\left(500 \mathrm{MHz} \mathrm{CDCl}_{3}\right): \delta$ $0.91(\mathrm{t}, 6 \mathrm{H}), 3.05(\mathrm{~m}, 4 \mathrm{H}), 3.68(\mathrm{~m}, 2 \mathrm{H}), 3.91(\mathrm{~m}, 2 \mathrm{H}), 6.86(\mathrm{t}, 2 \mathrm{H})$, 7.07 (d, 4H), $7.29(\mathrm{~m}, 4 \mathrm{H}) .{ }^{13} \mathrm{C}\left\{{ }^{1} \mathrm{H}\right\}$ NMR $\left(125 \mathrm{MHz}, \mathrm{CDCl}_{3}\right): \delta$ 14.25 (s), 39.72 (d), 46.28 (d), 115.05 (d), 118.55 (s), 129.00 (s).

N-Octadecyl-1,3-diphenyl-1,3,2-diazaphospholidin-2-amine (2b). 2-Chloro-1,3-diphenyl-1,3,2-diazaphospholidine (1.006 g, 3.600 $\mathrm{mol})$, triethylamine $(485 \mathrm{mg}, 4.80 \mathrm{mmol})$, and diethyl ether $(15 \mathrm{~mL})$ are loaded into a scintillation vial. Octadecylamine (1.080 g, 4.000 $\mathrm{mmol})$ is dissolved in diethyl ether $(5 \mathrm{~mL})$ and added dropwise. The mixture is allowed to stir for $20 \mathrm{~min}$. Precipitation of a white solid is observed immediately upon injection. The solid byproduct is filtered off. Volatiles are removed from the filtrate, and the resulting solid is recrystallized in THF at $-40{ }^{\circ} \mathrm{C}$ to yield a pale yellow solid. Yield $1.545 \mathrm{~g}(83 \%) .{ }^{31} \mathrm{P}\left\{{ }^{1} \mathrm{H}\right\} \mathrm{NMR}\left(500 \mathrm{MHz}, \mathrm{CDCl}_{3}\right): \delta 84.77 .{ }^{1} \mathrm{H}$ NMR $\left(202 \mathrm{MHz}, \mathrm{CDCl}_{3}\right): \delta 0.91(\mathrm{t}, 3 \mathrm{H}), 1.29(\mathrm{~m}, 33 \mathrm{H}), 2.58(\mathrm{~m}, 1 \mathrm{H})$, 2.75 (quin, $2 \mathrm{H}), 3.69(\mathrm{~m}, 2 \mathrm{H}), 3.83(\mathrm{~m}, 2 \mathrm{H}), 6.89(\mathrm{t}, 2 \mathrm{H}), 7.17(\mathrm{~m}$, 4H), $7.30(\mathrm{t}, 4 \mathrm{H}) .{ }^{13} \mathrm{C}\left\{{ }^{1} \mathrm{H}\right\}$ NMR (125 MHz, $\left.\mathrm{CDCl}_{3}\right): \delta 14.16(\mathrm{~s})$, $22.72(\mathrm{~s}), 26.78(\mathrm{~s}), 29.23(\mathrm{~s}), 29.40(\mathrm{~s}), 29.56(\mathrm{~d}), 29.72(\mathrm{~m}), 31.95$ (s), $32.11(\mathrm{~s}), 41.48(\mathrm{~s}), 46.66$ (d), 115.20 (d), 118.81 (s), 129.04 (s). Anal. Calcd for $\mathrm{C}_{32} \mathrm{H}_{52} \mathrm{~N}_{3} \mathrm{P}$ : C, 75.40; H, 10.28; N, 8.24. Found:
C, 75.70; $\mathrm{H}, 10.55 ; \mathrm{N}, 8.22$. MS (ASAP) $m / z$ : calcd for $\left[\mathrm{C}_{32} \mathrm{H}_{52} \mathrm{~N}_{3} \mathrm{P}+\right.$ $\mathrm{H}^{+}$], 510.3977; found, 510.3975.

N,N-Diethyl-1,3-diisopropyl-1,3,2-diazaphospholidin-2-amine (3a). 2-Chloro-1,3-diisopropyl-1,3,2-diazaphospholidine (569 mg, $2.70 \mathrm{mmol}$ ), triethylamine $(364 \mathrm{mg}, 3.6 \mathrm{mmol}$ ), and diethyl ether $(30 \mathrm{~mL})$ are loaded into a scintillation vial. Diethylamine $(0.31 \mathrm{~mL}$, $3.0 \mathrm{~mol}$ ) is added dropwise and allowed to stir for $20 \mathrm{~min}$. Precipitation of a white solid is observed immediately upon injection. The solid byproduct is filtered off. A second equivalent of triethylamine $(364 \mathrm{mg}, 3.60 \mathrm{mmol})$ is added followed by the dropwise addition of diethylamine $(0.31 \mathrm{~mL}, 3.0 \mathrm{mmol})$ and allowed to stir for $2 \mathrm{~h}$. The white precipitate is filtered. The resulting deep orange liquid is used without further purification. Yield $474 \mathrm{mg}$ (71\%). ${ }^{31} \mathrm{P}\left\{{ }^{1} \mathrm{H}\right\}$ NMR $\left(162 \mathrm{MHz}, \mathrm{C}_{6} \mathrm{D}_{6}\right): \delta 106.40 .{ }^{1} \mathrm{H}$ NMR (400 $\left.\mathrm{MHz}, \mathrm{C}_{6} \mathrm{D}_{6}\right): \delta 1.02(\mathrm{t}, 6 \mathrm{H}), 1.16(\mathrm{dd}, 12 \mathrm{H}), 2.80(\mathrm{~m}, 2 \mathrm{H}), 3.05(\mathrm{~m}$, $6 \mathrm{H}), 3.35(\mathrm{~m}, 2 \mathrm{H}) .{ }^{13} \mathrm{C}\left\{{ }^{1} \mathrm{H}\right\} \mathrm{NMR}\left(125 \mathrm{MHz}, \mathrm{C}_{6} \mathrm{D}_{6}\right): \delta 15.08(\mathrm{~d})$, 21.73 (dd), 39.09 (d), 44.33 (d), 46.94 (d). Anal. Calcd for $\mathrm{C}_{12} \mathrm{H}_{28} \mathrm{~N}_{3} \mathrm{P}: \mathrm{C}, 58.75 ; \mathrm{H}, 11.50 ; \mathrm{N}, 17.31$. Found: C, 59.13; H, 11.58; $\mathrm{N}, 17.17$. MS (ASAP) $m / z$ : calcd for $\left[\mathrm{C}_{12} \mathrm{H}_{28} \mathrm{~N}_{3} \mathrm{P}+\mathrm{H}^{+}\right]$, 246.2099; found, 246.2099.

$\mathrm{N}, \mathrm{N}$-Diethyl-1,3-dibenzyl-1,3,2-diazaphospholidin-2-amine (4a). 2-Chloro-1,3-dibenzyl-1,3,2-diazaphospholidine (1.106 g, $3.600 \mathrm{~mol}$ ), triethylamine $(485 \mathrm{mg}, 4.80 \mathrm{mmol})$, and diethyl ether $(20 \mathrm{~mL})$ are loaded into a scintillation vial. Diethylamine $(0.41 \mathrm{~mL}, 4.0 \mathrm{mmol})$ is added dropwise and allowed to stir for $20 \mathrm{~min}$. Precipitation of a white solid is observed immediately upon injection. The solid byproduct is filtered off. The resulting orange liquid is used without further purification. Yield $1.073 \mathrm{~g}(86 \%) .{ }^{31} \mathrm{P}\left\{{ }^{1} \mathrm{H}\right\} \mathrm{NMR}(202 \mathrm{MHz}$, $\left.\mathrm{CDCl}_{3}\right): \delta 113.88 .{ }^{1} \mathrm{H}$ NMR $\left(500 \mathrm{MHz}, \mathrm{CDCl}_{3}\right): \delta 1.08(\mathrm{t}, 6 \mathrm{H}), 2.90$ $(\mathrm{m}, 2 \mathrm{H}), 3.09$ (quin, $4 \mathrm{H}), 3.17(\mathrm{~m}, 2 \mathrm{H}), 3.94(\mathrm{dd}, 2 \mathrm{H}), 4.19$ (dd, $2 \mathrm{H}), 7.26(\mathrm{~m}, 2 \mathrm{H}), 7.35(\mathrm{~m}, 8 \mathrm{H}) .{ }^{13} \mathrm{C}\left\{{ }^{1} \mathrm{H}\right\}$ NMR $(125 \mathrm{MHz}$, $\mathrm{CDCl}_{3}$ ): $\delta 15.18$ (s), 43.93 (s), 44.58 (d), 48.78 (d), 127.57 (s), 128.12 (s), 128.63 (s). Anal. Calcd for $\mathrm{C}_{20} \mathrm{H}_{28} \mathrm{~N}_{3} \mathrm{P}$ : C, 70.36; H, 8.27; N, 12.31. Found: C, 70.27; H, 8.29; N, 12.07. MS (ASAP) $\mathrm{m} / z$ : calcd for $\left[\mathrm{C}_{20} \mathrm{H}_{28} \mathrm{~N}_{3} \mathrm{P}+\mathrm{H}^{+}\right]$, 342.2099; found, 342.2110.

N,N-Diethyl-1,3-dioctyl-1,3,2-diazaphospholidin-2-amine (5a). 2-Chloro-1,3-dioctyl-1,3,2-diazaphospholidine (1.106 g, $3.600 \mathrm{~mol})$, triethylamine (485 mg, $4.80 \mathrm{mmol})$, and diethyl ether $(20 \mathrm{~mL})$ are loaded into a scintillation vial. Diethylamine $(0.41 \mathrm{~mL}, 4.0 \mathrm{mmol})$ is added dropwise and allowed to stir for $2 \mathrm{~h}$. Precipitation of a white solid is observed immediately upon injection. The solid byproduct is filtered off. A second equivalent of triethylamine $(485 \mathrm{mg}, 4.80$ $\mathrm{mmol}$ ) is added followed by the dropwise addition of diethylamine $(0.41 \mathrm{~mL}, 4.0 \mathrm{mmol})$ and allowed to stir for $2 \mathrm{~h}$. The white precipitate is filtered. The resulting pale yellow liquid is used without further purification. Yield $1.791 \mathrm{~g}(90 \%) .{ }^{31} \mathrm{P}\left\{{ }^{1} \mathrm{H}\right\}$ NMR $\left(202 \mathrm{MHz}, \mathrm{C}_{6} \mathrm{D}_{6}\right): \delta$ 113.22. ${ }^{1} \mathrm{H}$ NMR $\left(500 \mathrm{MHz}, \mathrm{C}_{6} \mathrm{D}_{6}\right): \delta 0.90(\mathrm{t}, 6 \mathrm{H}), 1.03(\mathrm{t}, 6 \mathrm{H}), 1.29$ $(\mathrm{m}, 20 \mathrm{H}), 1.59(\mathrm{~m}, 4 \mathrm{H}), 2.92(\mathrm{~m}, 6 \mathrm{H}), 3.07$ (quin, $4 \mathrm{H}), 3.16(\mathrm{~m}$, $2 \mathrm{H}) .{ }^{13} \mathrm{C}\left\{{ }^{1} \mathrm{H}\right\} \operatorname{NMR}\left(125 \mathrm{MHz}, \mathrm{C}_{6} \mathrm{D}_{6}\right): \delta 14.00(\mathrm{~s}), 15.17(\mathrm{~s}), 22.74$ (s), 27.29 (s), 29.54 (d), 29.75 (d), 31.93 (s), 39.20 (d), 48.00 (d), 49.60 (d). Anal. Calcd for $\mathrm{C}_{20} \mathrm{H}_{28} \mathrm{~N}_{3} \mathrm{P}: \mathrm{C}, 68.52 ; \mathrm{H}, 12.55 ; \mathrm{N}, 10.90$. Found: C, 68.39; H, 12.51; N, 10.82. MS (ASAP) $\mathrm{m} / z$ : calcd for $\left[\mathrm{C}_{22} \mathrm{H}_{49} \mathrm{~N}_{3} \mathrm{P}+\mathrm{H}^{+}\right], 386.3664$; found, 386.3666 .

Precursor Conversion Kinetics. A three-neck round-bottom flask is loaded with indium(III) iodide $(112 \mathrm{mg}, 0.230 \mathrm{mmol})$, zinc(II) chloride $(153 \mathrm{mg}, 1.13 \mathrm{mmol})$, and oleylamine (3.659 g, $4.500 \mathrm{~mL}, 13.70 \mathrm{mmol}$ ) and outfitted with a glass adapter for a temperature probe. The desired phosphorus precursor $(0.9 \mathrm{~mol}$ of phosphorus) and trioctylamine (405 $\mathrm{mg}, 0.500 \mathrm{~mL}, 1.10 \mathrm{mmol}$ ) or tetraethylene glycol dimethyl ether (in the case of $2 \mathrm{a}, 504.5 \mathrm{mg}$, $0.5000 \mathrm{~mL}, 1.100 \mathrm{mmol}$ ) are loaded into a $4 \mathrm{~mL}$ vial. Both vessels are transferred to a Schlenk line and placed under argon. The three-neck round-bottom flask was brought to the desired temperature, and the 4 $\mathrm{mL}$ vial was brought to $100{ }^{\circ} \mathrm{C}$ (in some cases to dissolve the phosphorus precursor). The phosphorus precursor solution was quickly injected into the mixture of metal salts and allowed to react for the appropriate amount of time. Quantitative aliquots are taken sequentially throughout the course of the reaction for analysis by $\mathrm{UV}-$ vis and NMR spectroscopy $\left({ }^{31} \mathrm{P}\right.$ and $\left.{ }^{1} \mathrm{H}\right)$. 
Aliquots $(0.1 \mathrm{~mL})$ for UV-vis absorption spectroscopy measurements are injected into a preweighed vial in air and subsequently diluted with a known amount of toluene $(5 \mathrm{~mL})$. Aliquots $(0.1 \mathrm{~mL})$, for ${ }^{1} \mathrm{H}$ and ${ }^{31} \mathrm{P}$ NMR analyses, are injected into a septum-sealed NMR tube containing a stock solution $(30 \mathrm{mM})$ of tri- $n$-octylphosphine oxide in $\mathrm{C}_{6} \mathrm{D}_{6}$. Upon injection, the NMR tube is placed into a $\mathrm{CO}_{2(\mathrm{~s})}$-acetone bath to prevent further transamination. ${ }^{31} \mathrm{P}$ NMR spectra are collected without the decoupling of ${ }^{1} \mathrm{H}$ nuclei and with delay times $(7 \mathrm{~s})$ that are $5 \times$ longer than the longest $\mathrm{T} 1$ relaxation time $(1.4 \mathrm{~s})$ to assure that the measurements are quantitative. Exact concentrations of reaction species are determined by comparing relative integrations of their ${ }^{31} \mathrm{P}$ NMR spectroscopy signals to that of the tri- $n$-octylphosphine oxide- $\mathrm{C}_{6} \mathrm{D}_{6}$ stock solution. ${ }^{1} \mathrm{H}$ NMR spectra are also collected.

Determination of Nanocrystal Size and Yield. The average nanocrystal size in each aliquot is calculated from the peak wavelength of the first excitonic transition using a previously reported InP nanocrystal sizing curve. ${ }^{28}$ The tetrahedral shape model was chosen for convenience (a new curve relating both size/shape to the excitonic transition energy was not attempted). This approach intentionally underestimates the volume of large nanocrystals; using the sizing curve for nanocrystals with a spherical shape published by the same authors, instead, would magnify the conclusion that nucleation is continuous and growth is size dependent. Thus, our size estimates are conservative and intended to increase the confidence in our mechanistic model (see the Supporting Information for further discussion of error analysis).

The concentration of $[\mathrm{InP}]_{i}$ is determined from the absorbance at $\lambda$ $=413 \mathrm{~nm}$ using a previously reported extinction coefficient (see the Supporting Information for details). ${ }^{27}$ The concentration of nanoparticles formed is extracted according to previously described methods. ${ }^{27}$

Dependence of the Reaction Rate on Diamine Concentration. A three-neck round-bottom flask is loaded with indium iodide (112 mg, $0.230 \mathrm{mmol}$ ), zinc chloride (153 mg, $1.13 \mathrm{mmol}$ ), the desired diamine $(0.45 \mathrm{mmol})$, and oleylamine $(3.659 \mathrm{~g}, 4.500 \mathrm{~mL}$, $13.70 \mathrm{mmol}$ ) and outfitted with a glass adapter for a temperature probe. Tris(dimethylamino)phosphine $(147 \mathrm{mg}, 0.900 \mathrm{mmol})$ and trioctylamine $(405 \mathrm{mg}, 0.500 \mathrm{~mL}, 1.14 \mathrm{mmol})$ are loaded into a separate $4 \mathrm{~mL}$ vial. The remaining procedures are identical to those discussed above.

Purification of InP Nanocrystals. All purification steps were performed in air. After returning to room temperature, the reaction mixture is precipitated using an excess of acetone $(\sim 35 \mathrm{~mL})$ and centrifuged. The supernatant is disposed of, and the colored residue is redispersed in toluene $(\sim 3 \mathrm{~mL})$ and subsequently precipitated with acetone $(\sim 30 \mathrm{~mL})$. The nanocrystals are washed an additional three times with toluene and acetone.

ZnSe Shelling of InP Nanocrystals. InP nanocrystals are shelled with $\mathrm{ZnSe}$ according to a previously reported procedure. ${ }^{27}$

\section{ASSOCIATED CONTENT}

\section{(s) Supporting Information}

The Supporting Information is available free of charge at https://pubs.acs.org/doi/10.1021/acs.chemmater.0c01561.

Supplementary figures (S1-S14), discussions of yield variability, calculation of nanocrystal concentration and nucleation fraction, $Q_{0}$ fits, traces associated with reaction aliquots, and ${ }^{31} \mathrm{P},{ }^{1} \mathrm{H}$, and ${ }^{13} \mathrm{C}$ NMR spectra for all newly synthesized compounds (PDF)

\section{AUTHOR INFORMATION}

\section{Corresponding Author}

Jonathan S. Owen - Department of Chemistry, Columbia University, New York, New York 10027, United States; 이 orcid.org/0000-0001-5502-3267; Email: jso2115@ columbia.edu

\section{Authors}

Brandon M. McMurtry - Department of Chemistry, Columbia University, New York, New York 10027, United States; (1) orcid.org/0000-0002-3624-941X

Kevin Qian - Department of Chemistry, Columbia University, New York, New York 10027, United States

Joseph K. Teglasi - Department of Chemistry, Columbia University, New York, New York 10027, United States

Anindya K. Swarnakar - Department of Chemistry, Columbia University, New York, New York 10027, United States

Jonathan De Roo - Department of Chemistry, Columbia University, New York, New York 10027, United States; Department of Chemistry, University of Basel, Basel 4058, Switzerland; o orcid.org/0000-0002-1264-9312

Complete contact information is available at:

https://pubs.acs.org/10.1021/acs.chemmater.0c01561

\section{Notes}

The authors declare no competing financial interest.

\section{ACKNOWLEDGMENTS}

This work was supported by the National Science Foundation under award number 1710352. We would like to acknowledge Columbia University's Nanoscience Initiative for use of its shared facilities and Amirali Zangiabadi for assistance in collecting transmission electron microscopy and scanning transmission electron microcopy images. Powder X-ray diffraction patterns were collected at Columbia University's Shared Materials Characterization Laboratory. We would like to acknowledge Leslie S. Hamachi and Michael L. Steigerwald for helpful discussion.

\section{REFERENCES}

(1) Cao, F.; Wang, S.; Wang, F.; Wu, Q.; Zhao, D.; Yang, X. A Layer-by-Layer Growth Strategy for Large-Size InP/ZnSe/ZnS CoreShell Quantum Dots Enabling High-Efficiency Light-Emitting Diodes. Chem. Mater. 2018, 30, 8002-8007.

(2) Dupont, D.; Tessier, M. D.; Smet, P. F.; Hens, Z. Indium Phosphide-Based Quantum Dots with Shell-Enhanced Absorption for Luminescent Down-Conversion. Adv. Mater. 2017, 29, 1700686.

(3) Won, Y.-H.; Cho, O.; Kim, T.; Chung, D.-Y.; Kim, T.; Chung, H.; Jang, H.; Lee, J.; Kim, D.; Jang, E. Highly Efficient and Stable $\mathrm{InP} / \mathrm{ZnSe} / \mathrm{ZnS}$ Quantum Dot Light-Emitting Diodes. Nature 2019, 575, 634-638.

(4) Choi, H. S.; Kim, Y.; Park, J. C.; Oh, M. H.; Jeon, D. Y.; Nam, Y. $\mathrm{S}$. Highly Luminescent, Off-Stoichiometric $\mathrm{CuX}$ in $\mathrm{YS}_{2} / \mathrm{ZnS}$ Quantum Dots for near-Infrared Fluorescence Bio-Imaging. RSC Adv. 2015, 5, 43449-43455.

(5) Gao, X.; Cui, Y.; Levenson, R. M.; Chung, L. W. K.; Nie, S. In Vivo Cancer Targeting and Imaging with Semiconductor Quantum Dots. Nat. Biotechnol. 2004, 22, 969-976.

(6) Tamang, S.; Lincheneau, C.; Hermans, Y.; Jeong, S.; Reiss, P. Chemistry of InP Nanocrystal Syntheses. Chem. Mater. 2016, 28, 2491-2506.

(7) Chen, O.; Zhao, J.; Chauhan, V. P.; Cui, J.; Wong, C.; Harris, D. K.; Wei, H.; Han, H.-S.; Fukumura, D.; Jain, R. K.; Bawendi, M. G. Compact High-Quality CdSe-CdS Core-Shell Nanocrystals with Narrow Emission Linewidths and Suppressed Blinking. Nat. Mater. 2013, 12, 445-451.

(8) Ramasamy, P.; Kim, N.; Kang, Y.-S.; Ramirez, O.; Lee, J.-S. Tunable, Bright, and Narrow-Band Luminescence from Colloidal Indium Phosphide Quantum Dots. Chem. Mater. 2017, 29, 68936899.

(9) Ramasamy, P.; Ko, K.-J.; Kang, J.-W.; Lee, J.-S. Two-Step “SeedMediated" Synthetic Approach to Colloidal Indium Phosphide 
Quantum Dots with High-Purity Photo- and Electroluminescence. Chem. Mater. 2018, 30, 3643-3647.

(10) Li, Y.; Hou, X.; Dai, X.; Yao, Z.; Lv, L.; Jin, Y.; Peng, X. Stoichiometry-Controlled InP-Based Quantum Dots: Synthesis, Photoluminescence, and Electroluminescence. J. Am. Chem. Soc. 2019, 141, 6448-6452.

(11) Xu, Z.; Li, Y.; Li, J.; Pu, C.; Zhou, J.; Lv, L.; Peng, X. Formation of Size-Tunable and Nearly Monodisperse InP Nanocrystals: Chemical Reactions and Controlled Synthesis. Chem. Mater. 2019, 31, 5331-5341.

(12) Abe, S.; Čapek, R. K.; De Geyter, B.; Hens, Z. Tuning the Postfocused Size of Colloidal Nanocrystals by the Reaction Rate: From Theory to Application. ACS Nano 2012, 6, 42-53.

(13) Campos, M. P.; Hendricks, M. P.; Beecher, A. N.; Walravens, W.; Swain, R. A.; Cleveland, G. T.; Hens, Z.; Sfeir, M. Y.; Owen, J. S. A Library of Selenourea Precursors to PbSe Nanocrystals with Size Distributions near the Homogeneous Limit. J. Am. Chem. Soc. 2017, 139, 2296-2305.

(14) Hamachi, L. S.; Jen-La Plante, I.; Coryell, A. C.; De Roo, J.; Owen, J. S. Kinetic Control over CdS Nanocrystal Nucleation Using a Library of Thiocarbonates, Thiocarbamates, and Thioureas. Chem. Mater. 2017, 29, 8711-8719.

(15) Hendricks, M. P.; Campos, M. P.; Cleveland, G. T.; Jen-La Plante, I.; Owen, J. S. A Tunable Library of Substituted Thiourea Precursors to Metal Sulfide Nanocrystals. Science 2015, 348, 12261230.

(16) LaMer, V. K.; Dinegar, R. H. Theory, Production and Mechanism of Formation of Monodispersed Hydrosols. J. Am. Chem. Soc. 1950, 72, 4847-4854.

(17) Owen, J. S.; Chan, E. M.; Liu, H.; Alivisatos, A. P. Precursor Conversion Kinetics and the Nucleation of Cadmium Selenide Nanocrystals. J. Am. Chem. Soc. 2010, 132, 18206-18213.

(18) Gary, D. C.; Cossairt, B. M. Role of Acid in Precursor Conversion During InP Quantum Dot Synthesis. Chem. Mater. 2013, 25, 2463-2469.

(19) Gary, D. C.; Glassy, B. A.; Cossairt, B. M. Investigation of Indium Phosphide Quantum Dot Nucleation and Growth Utilizing Triarylsilylphosphine Precursors. Chem. Mater. 2014, 26, 1734-1744.

(20) Gary, D. C.; Terban, M. W.; Billinge, S. J. L.; Cossairt, B. M. Two-Step Nucleation and Growth of InP Quantum Dots via MagicSized Cluster Intermediates. Chem. Mater. 2015, 27, 1432-1441.

(21) Koh, S.; Eom, T.; Kim, W. D.; Lee, K.; Lee, D.; Lee, Y. K.; Kim, H.; Bae, W. K.; Lee, D. C. Zinc-Phosphorus Complex Working as an Atomic Valve for Colloidal Growth of Monodisperse Indium Phosphide Quantum Dots. Chem. Mater. 2017, 29, 6346-6355.

(22) Tessier, M. D.; De Nolf, K.; Dupont, D.; Sinnaeve, D.; De Roo, J.; Hens, Z. Aminophosphines: A Double Role in the Synthesis of Colloidal Indium Phosphide Quantum Dots. J. Am. Chem. Soc. 2016, 138, 5923-5929.

(23) Xie, L.; Harris, D. K.; Bawendi, M. G.; Jensen, K. F. Effect of Trace Water on the Growth of Indium Phosphide Quantum Dots. Chem. Mater. 2015, 27, 5058-5063.

(24) Franke, D.; Harris, D. K.; Xie, L.; Jensen, K. F.; Bawendi, M. G. The Unexpected Influence of Precursor Conversion Rate in the Synthesis of III-V Quantum Dots. Angew. Chem., Int. Ed. 2015, 54, 14299-14303.

(25) Harris, D. K.; Bawendi, M. G. Improved Precursor Chemistry for the Synthesis of III-V Quantum Dots. J. Am. Chem. Soc. 2012, 134, 20211-20213.

(26) Joung, S.; Yoon, S.; Han, C.-S.; Kim, Y.; Jeong, S. Facile Synthesis of Uniform Large-Sized InP Nanocrystal Quantum Dots Using Tris(tert-butyldimethylsilyl) Phosphine. Nanoscale Res. Lett. 2012, 7, 93-100.

(27) Tessier, M. D.; Dupont, D.; De Nolf, K.; De Roo, J.; Hens, Z. Economic and Size-Tunable Synthesis of $\mathrm{InP} / \mathrm{ZnE}(\mathrm{E}=\mathrm{S}, \mathrm{Se})$ Colloidal Quantum Dots. Chem. Mater. 2015, 27, 4893-4898.

(28) Kim, K.; Yoo, D.; Choi, H.; Tamang, S.; Ko, J.-H.; Kim, S.; Kim, Y.-H.; Jeong, S. Halide-Amine Co-Passivated Indium Phosphide
Colloidal Quantum Dots in Tetrahedral Shape. Angew. Chem., Int. Ed. 2016, 55, 3714-3718.

(29) Buffard, A.; Dreyfuss, S.; Nadal, B.; Heuclin, H.; Xu, X.; Patriarche, G.; Mézailles, N.; Dubertret, B. Mechanistic Insight and Optimization of InP Nanocrystals Synthesized with Aminophosphines. Chem. Mater. 2016, 28, 5925-5934.

(30) Laufersky, G.; Bradley, S.; Frécaut, E.; Lein, M.; Nann, T. Unraveling Aminophosphine Redox Mechanisms for Glovebox-Free InP Quantum Dot Syntheses. Nanoscale 2018, 10, 8752-8762.

(31) Bent, E. G.; Haltiwanger, R. C.; Norman, A. D. Intermediates in the 1,2-Diaminobenzene/Tris(diethylamino)phosphine Transamination Reaction. Inorg. Chem. 1990, 29, 4310-4318.

(32) Hill, T. G.; Haltiwanger, R. C.; Thompson, M. L.; Katz, S. A.; Norman, A. D. Cis/Trans Isomerization and Conformational Properties of 2, 4-Bis (primary amino)-1, 3, 2, 4-diazadiphosphetidines. Inorg. Chem. 1994, 33, 1770-1777.

(33) Abrams, M. B.; Scott, B. L.; Baker, R. T. Sterically Tunable Phosphenium Cations: Synthesis and Characterization of Bis(arylamino)phosphenium Ions, Phosphinophosphenium Adducts, and the First Well-Defined Rhodium Phosphenium Complexes. Organometallics 2000, 19, 4944-4956.

(34) Huang, H.; Kang, J. Y. Mitsunobu Reaction Using Basic Amines as Pronucleophiles. J. Org. Chem. 2017, 82, 6604-6614.

(35) Wucher, P.; Roesle, P.; Falivene, L.; Cavallo, L.; Caporaso, L.; Göttker-Schnetmann, I.; Mecking, S. Controlled Acrylate Insertion Regioselectivity in Diazaphospholidine-Sulfonato Palladium(II) Complexes. Organometallics 2012, 31, 8505-8515.

(36) Nifantev, É. E.; Sorokina, S. F.; Vorobeva, L. A.; Bekker, A. R., 1,3-Dibenzyl-1,3,2-diazaphospholidines and -Hexahydro-1,3,2-di- azaphosphorines. Russ. J. Gen. Chem. 1985, 55, 269-275. DOI: 10.1002/ chin. 198540252

(37) Friedfeld, M. R.; Johnson, D. A.; Cossairt, B. M. Conversion of InP Clusters to Quantum Dots. Inorg. Chem. 2018, 58, 803-810.

(38) The hwhm values reported here are $\sim 30 \%$ broader than the original report, which appears to be a consequence of the different methods to analyze the spectra. The previous study measured the fwhm by calculating the first derivative of the absorbance spectrum and determining a maximum/minimum to extract the inflection point in the lowest energy optical transition. This analysis does not accurately capture the behavior of more complex peak shapes nor the contribution of overlapping transitions on the higher energy side of the excitonic features. Using this method to analyze the spectra reported here gave values equal to or smaller than the original report.

(39) Owen, J.; Brus, L. Chemical Synthesis and Luminescence Applications of Colloidal Semiconductor Quantum Dots. J. Am. Chem. Soc. 2017, 139, 10939-10943.

(40) Vikram, A.; Zahid, A.; Bhargava, S. S.; Keating, L. P.; Sutrisno, A.; Khare, A.; Trefonas, P.; Shim, M.; Kenis, P. J.A. Mechanistic Insight into Size-focused Growth of Indium Phosphide Nanocrystals in the Presence of Trace Water. Chem. Mater. 2020, 32, 3577-3584.

(41) Xie, L.; Shen, Y.; Franke, D.; Sebastián, V.; Bawendi, M. G.; Jensen, K. F. Characterization of Indium Phosphide Quantum Dot Growth Intermediates Using MALDI-TOF Mass Spectrometry. J. Am. Chem. Soc. 2016, 138, 13469-13472.

(42) Sugimoto, T.; Shiba, F. Spontaneous Nucleation of Monodisperse Silver Halide Particles from Homogeneous Gelatin Solution II: Silver Bromide. Colloids Surf., A 2000, 164, 205-215.

(43) Sugimoto, T.; Shiba, F.; Sekiguchi, T.; Itoh, H. Spontaneous Nucleation of Monodisperse Silver Halide Particles from Homogeneous Gelatin Solution I: Silver Chloride. Colloids Surf., A 2000, 164, 183-203.

(44) Hamachi, L. S.; Yang, H.; Jen-La Plante, I.; Saenz, N.; Qian, K.; Campos, M. P.; Cleveland, G. T.; Rreza, I.; Oza, A.; Walravens, W.; Chan, E. M.; Hens, Z.; Crowther, A. C.; Owen, J. S. Precursor Reaction Kinetics Control Compositional Grading and Size of $\mathrm{CdSe}_{1-\mathrm{X}} \mathrm{S}_{\mathrm{X}}$ Nanocrystal Heterostructures. Chem. Sci. 2019, 10, 6539-6552. 
(45) Chu, D. B. K.; Owen, J. S.; Peters, B. Nucleation and Growth Kinetics from Lamer Burst Data. J. Phys. Chem. A 2017, 121, 75117517.

(46) Rempel, J. Y.; Bawendi, M. G.; Jensen, K. F. Insights into the Kinetics of Semiconductor Nanocrystal Nucleation and Growth. J. Am. Chem. Soc. 2009, 131, 4479-4489.

(47) Kim, Y.; Ham, S.; Jang, H.; Min, J. H.; Chung, H.; Lee, J.; Kim, D.; Jang, E. Bright and Uniform Green Light Emitting InP/ZnSe/ZnS Quantum Dots for Wide Color Gamut Displays. ACS Appl. Nano Mater. 2019, 2, 1496-1504.

(48) Liu, Z.; Kumbhar, A.; Xu, D.; Zhang, J.; Sun, Z.; Fang, J. Coreduction Colloidal Synthesis of III-V Nanocrystals: The Case of InP. Angew. Chem., Int. Ed. 2008, 47, 3540-3542.

(49) Shen, W.; Tang, H.; Yang, X.; Cao, Z.; Cheng, T.; Wang, X.; Tan, Z.; You, J.; Deng, Z. Synthesis of Highly Fluorescent InP/ZnS Small-Core/Thick-Shell Tetrahedral-Shaped Quantum Dots for Blue Light-Emitting Diodes. J. Mater. Chem. C 2017, 5, 8243-8249.

(50) Baquero, E. A.; Virieux, H.; Swain, R. A.; Gillet, A.; CrosGagneux, A.; Coppel, Y.; Chaudret, B.; Nayral, C.; Delpech, F. Synthesis of Oxide-Free InP Quantum Dots: Surface Control and $\mathrm{H}_{2}-$ Assisted Growth. Chem. Mater. 2017, 29, 9623-9627.

(51) Yin, Y.; Alivisatos, A. P. Colloidal Nanocrystal Synthesis and the Organic-Inorganic Interface. Nature 2005, 437, 664-670.

(52) Whitehead, C. B.; Özkar, S.; Finke, R. G. LaMer's 1950 Model for Particle Formation of Instantaneous Nucleation and DiffusionControlled Growth: A Historical Look at the Model's Origins, Assumptions, Equations, and Underlying Sulfur Sol Formation Kinetics Data. Chem. Mater. 2019, 31, 7116-7132.

(53) Sugimoto, T. Underlying Mechanisms in Size Control of Uniform Nanoparticles. J. Colloid Interface Sci. 2007, 309, 106-118.

(54) Peng, X.; Wickham, J.; Alivisatos, A. P. Kinetics of II-VI and IIIV Colloidal Semiconductor Nanocrystal Growth: "Focusing" of Size Distributions. J. Am. Chem. Soc. 1998, 120, 5343-5344.

(55) Reiss, H. The Growth of Uniform Colloidal Dispersions. J. Chem. Phys. 1951, 19, 482-487.

(56) Cussler, E. L. Diffusion: Mass Transfer in Fluid Systems; Cambridge University Press: Cambridge, 2009.

(57) Handwerk, D. R.; Shipman, P. D.; Whitehead, C. B.; Özkar, S.; Finke, R. G. Mechanism-Enabled Population Balance Modeling of Particle Formation en Route to Particle Average Size and Size Distribution Understanding and Control. J. Am. Chem. Soc. 2019, 141, $15827-15839$.

(58) Kim, J. Y.; Steeves, A. H.; Kulik, H. J. Harnessing Organic Ligand Libraries for First-Principles Inorganic Discovery: Indium Phosphide Quantum Dot Precursor Design Strategies. Chem. Mater. 2017, 29, 3632-3643.

(59) Zhao, Q.; Kulik, H. J. Electronic Structure Origins of SurfaceDependent Growth in III-V Quantum Dots. Chem. Mater. 2018, 30, $7154-7165$.

(60) Beecher, A. N.; Yang, X.; Palmer, J. H.; LaGrassa, A. L.; Juhas, P.; Billinge, S. J. L.; Owen, J. S. Atomic Structures and Gram Scale Synthesis of Three Tetrahedral Quantum Dots. J. Am. Chem. Soc. 2014, 136, 10645-10653.

(61) Bullen, C. R.; Mulvaney, P. Nucleation and Growth Kinetics of CdSe Nanocrystals in Octadecene. Nano Lett. 2004, 4, 2303-2307.

(62) van Embden, J.; Mulvaney, P. Nucleation and Growth of CdSe Nanocrystals in a Binary Ligand System. Langmuir 2005, 21, 1022610233.

(63) Yordanov, G. G.; Yoshimura, H.; Dushkin, C. D. Fine Control of the Growth and Optical Properties of CdSe Quantum Dots by Varying the Amount of Stearic Acid in a Liquid Paraffin Matrix. Colloids Surf., A 2008, 322, 177-182.

(64) Yu, W. W.; Peng, X. Formation of High-Quality CdS and Other II-VI Semiconductor Nanocrystals in Noncoordinating Solvents: Tunable Reactivity of Monomers. Angew. Chem., Int. Ed. 2002, 41, 2368-2371.

(65) Gary, D. C.; Flowers, S. E.; Kaminsky, W.; Petrone, A.; Li, X.; Cossairt, B. M. Single-Crystal and Electronic Structure of a $1.3 \mathrm{~nm}$
Indium Phosphide Nanocluster. J. Am. Chem. Soc. 2016, 138, 15101513.

(66) Abécassis, B.; Bouet, C.; Garnero, C.; Constantin, D.; Lequeux, N.; Ithurria, S.; Dubertret, B.; Pauw, B. R.; Pontoni, D. Real-Time In Situ Probing of High-Temperature Quantum Dots Solution Synthesis. Nano Lett. 2015, 15, 2620-2626.

(67) Jasieniak, J.; Smith, L.; van Embden, J.; Mulvaney, P.; Califano, M. Re-Examination of the Size-Dependent Absorption Properties of CdSe Quantum Dots. J. Phys. Chem. C 2009, 113, 19468-19474.

(68) Baranov, D.; Lynch, M. J.; Curtis, A. C.; Carollo, A. R.; Douglass, C. R.; Mateo-Tejada, A. M.; Jonas, D. M. Purification of Oleylamine for Materials Synthesis and Spectroscopic Diagnostics for Trans Isomers. Chem. Mater. 2019, 31, 1223-1230.

(69) Block, M. A. B.; Hecht, S. Alternating (Squaraine-Receptor) Sensory Polymers: Modular One-Pot Synthesis and Signal Transduction Via Conformationally Controlled Exciton Interaction. Macromolecules 2004, 37, 4761-4769.

(70) Marre, M. R.; Sanchez, M.; Brazier, J. F.; Wolf, R.; Bellan, J. La Liaison Phosphazène Dans Quelques Nouveaux Iminophospholanes. Diversité De Comportement Réactionnel. Can. J. Chem. 1982, 60, 456-468.

(71) Krysiak, J.; Lyon, C.; Baceiredo, A.; Gornitzka, H.; Mikolajczyk, M.; Bertrand, G. Stable Optically Pure Phosphino(silyl)carbenes: Reagents for Highly Enantioselective Cyclopropanation Reactions. Chem.-Eur. J. 2004, 10, 1982-1986. 